2013

\title{
THE ROLE OF ECTOMYCORRHIZAL FUNGI ON FERTILIZED AND UNFERTILIZED NURSERY GROWN WHITE SPRUCE
}

Alistair James Henry Smith II Michigan Technological University

Follow this and additional works at: https://digitalcommons.mtu.edu/etds

Part of the Forest Sciences Commons

Copyright 2013 Alistair James Henry Smith II

Recommended Citation

Smith, Alistair James Henry II, "THE ROLE OF ECTOMYCORRHIZAL FUNGI ON FERTILIZED AND UNFERTILIZED NURSERY GROWN WHITE SPRUCE", Master's Thesis, Michigan Technological University, 2013.

https://doi.org/10.37099/mtu.dc.etds/583

Follow this and additional works at: https://digitalcommons.mtu.edu/etds

8 Part of the Forest Sciences Commons 


\title{
THE ROLE OF ECTOMYCORRHIZAL FUNGI ON FERTILIZED AND UNFERTILIZED NURSERY GROWN WHITE SPRUCE
}

\author{
By
}

Alistair J. H. Smith II

\begin{abstract}
A THESIS
Submitted in partial fulfillment of the requirements for the degree of MASTER OF SCIENCE

In Forest Ecology and Management
\end{abstract}

MICHIGAN TECHNOLOGICAL UNIVERSITY

2013 
This thesis has been approved in partial fulfillment of the requirements for the Degree of MASTER OF SCIENCE in Forest Ecology and Management.

\title{
School of Forest Resources and Environmental Science
}

\author{
Thesis Co-Advisor: $\quad$ Erik Lilleskov \\ Thesis Co-Advisor: $\quad$ Helja-Sisko Helmisaari \\ Committee Member: $\quad$ Dana Richter \\ Committee Member: Amy Marcarelli
}

School Dean: Terry Sharik 


\section{Table of Contents-}

Table of contents........................................... 3

Table of figures.......................................... 4

Preface..................................................... 6

$0-$ Abstract.................................................... 7

1 - Introduction............................................... 8

2- Methods................................................. 10

2.1- Sample collection........................................ 10

2.2-Outplanting ......................................... 10

2.3-Sample harvest........................................ 11

2.4- Fungal identification........................................... 12

2.5-Morphological identification............................ 13

2.6- Statistical tests....................................... 13

3- Results................................................ 14

3.1- Fungal community composition ............................ 14

3.2- Foliar chemistry........................................ 15

3.3- Fungal community effects on foliar nutrient concentration...... 16

3.4- Fungal species effect on foliar nutrient concentration........... 16

3.5- Fungal community effect on foliar nutrient content............. 17

3.6- Fungal species effects on foliar nutrient content ............... 17

3.7- Treatment effects on biomass and root:shoot ratios.............. 18

3.8- Community effects on biomass and root:shoot ratios............ 18

3.9- Fungal species effects on biomass and root:shoot ratios........ 18

4- Discussion............................................... 19

4.1- Individual species effects on seedling chemistry/stoichiometry... 19

4.2- Individual species effects on plant development .............. 22

4.3- Practical applications of fungi in field versus nursery settings... 22

5-Conclusions.............................................. 24

6- References.............................................. 25 


\section{Table of Figures-}

Fig 1-Seedling collection at Toumey Nursery, Watersmeet, MI................. 29

Fig 2- White initial morphotype....................................................... 30

Fig 3- Brown initial morphotype ..........................................................

Fig 4- Yellow initial morphotype............................................................... 32

Table 1-Scott's champion fertilizer composition ........................................ 33

Table 2- Root tip percentage colonization................................................ 34

Table 3- Thermocycler program ........................................................ $\quad 35$

Fig 5- Amphinema phylogenetic tree .................................................... 36

Fig 6- Amphinema sp. 1 root tip................................................................. 37

Fig 7- Amphinema sp. 1 warty texture.................................................. 38

Fig 8- Amphinema sp. 1 H anastomoses.................................................... 39

Fig 9- Amphinema sp. 1 rhizomorph ................................................ 40

Fig 10- Amphinema sp. 5 root tip..................................................... 41

Fig 11- Amphinema sp. 5 H anastomoses................................................ 42

Fig 12- Thelephora terrestris root tip................................................. 43

Fig 13- Thelephora terrestris cystidia .................................................. 44

Fig 14- Thelephora terrestris rhizomorph.......................................... 45

Fig 15- $N, K, P, M g, S$, and Ca seedling concentration means...................... 46

Fig 16- $\mathrm{Mn}, \mathrm{Cu}, \mathrm{Al}, \mathrm{Zn}, \mathrm{Na}$, and Fe seedlings concentration means............... 47

Table 4- Foliar nutrient concentration of seedlings................................... 48

Fig 17- NMDS for unfertilized seedling foliar nutrient concentration......... 49

Fig 18- NMDS for fertilized seedling foliar nutrient concentration............. 50

Fig 19-Regression for foliar concentration of $N$ in unfertilized seedlings... $\quad 51$

Fig 20-Regression for foliar concentration of $P$ in fertilized seedlings....... $\quad 52$

Fig 21- Regression for foliar concentration of B in fertilized seedlings....... 52

Fig 22-Regression for foliar concentration of $\mathrm{Mg}$ in fertilized seedlings.... $\quad 53$

Fig 23-Regression for foliar concentration of Mn in fertilized seedlings...... 53

Table 5- Table of foliar nutrient concentration ratios................................ 54

Fig 24- Linear regression of N:P ratio in unfertilized seedlings................... 
Fig 25- Linear regression of N:P ratio in fertilized seedlings........................ 56

Fig 26- NMDS for unfertilized seedling foliar nutrient content....................

Fig 27- NMDS for fertilized seedling foliar nutrient content....................... 58

Fig 28- Regression for foliar content of B in fertilized seedlings.................. 59

Fig 29- Regression for foliar content of Mn in fertilized seedlings............... $\quad 60$

Fig 30- Regression for foliar content of $\mathrm{Mg}$ in fertilized seedlings................ $\quad 60$

Fig 31- Regression for foliar content of $P$ in unfertilized seedlings............... $\quad 61$

Table 6- Means and standard errors for seedling growth............................ $\quad 62$

Fig 32- NMDS for unfertilized seedling root:shoot ratios.............................. 63

Fig 33- NMDS for fertilized seedling root:shoot ratios..................................... 64

Fig 34- Linear regression for root:shoot ratios in unfertilized seedlings..... $\quad 65$

Fig 35- Linear regression for root:shoot ratios in fertilized seedlings......... $\quad 66$

Table 7- Growth limiting nutrient concentrations.......................................... 67

Table 8- Inferred effects of ectomycorrhizal species...................................... 68 


\section{Preface}

Ectomycorrhizal fungi are a common occurrence in many ecosystems.

However, for how prevalent they may be, very little is known about plant/fungus interactions. It was the aim of Dr. Erik Lilleskov (Advising, protocol development, photographs of plant collection), Lynette Potvin (Sample processing), and myself (Sample collection, protocol development, sample processing, DNA extraction, DNA analysis, statistical work, and written paper) to attempt to fill in the knowledge gaps pertaining to ectomycorrhiza. We hope that this paper is an adequate first step. 


\section{0- Abstract}

Nursery grown seedlings are an essential part of the forestry industry. These seedlings are grown under high nutrient conditions caused by fertilization. Though grown in a controlled environment, symbionts such as ectomycorrhizal fungi (EcMF) are often found in these conditions. To examine the effects of EcMF in these conditions, colonized Picea glauca seedlings were collected from Toumey Nursery in Watersmeet, MI. After collection, the EcMF present were morphotyped, and seedlings with different morphotypes were divided equally into two treatment types- fertilized and unfertilized. Seedlings received treatment for one growing season. After that time, seedlings were collected, ectomycorrhizas identified using ${ }^{1}$ morphotyping and DNA sequencing, and seedlings were analyzed for differences in leaf nutrient concentration, content, root to shoot ratio, total biomass, and EcMF community structure.

DNA sequencing identified 5 unique species groups- Amphinema sp. 1,

Amphinema sp. 5, Thelephora terrestris, Sphaerosporella brunnea, and Boletus variipes. In the unfertilized treatment it was found that Amphinema sp. 1 strongly negatively impacted foliar $\mathrm{N}$ concentration. In fertilized seedlings, Thelephora terrestris had a strong negative impact on foliar phosphorus concentration, while Amphinema sp. 1 positively impacted foliar boron, magnesium, manganese, and phosphorus concentration. In terms of content, Amphinema sp. 1 led to significantly higher content of manganese and boron in fertilized treatments, as well as elevated phosphorus in unfertilized seedlings. Amphinema sp. 5 had a significant negative effect on phosphorus content. When examining root to shoot ratio and biomass, those seedlings with more nonmycorrhizal tips had a higher root to shoot ratio.

Findings from the study shed light on the interactions of the species. Amphinema sp. 5 shows very different functionality than Amphinema sp. 1. Amphinema sp. 1 appears to have the highest positive effect on seedling nutrition when in both fertilized and unfertilized environments. Amphinema sp. 5 and T.terrestris appear to behave parasitically in both fertilized and unfertilized conditions.

\footnotetext{
${ }^{1}$ The material contained in this chapter has been submitted to Forest Ecology and Management
} 


\section{1- Introduction}

The use of nursery stock seedlings in the forestry industry has been common practice for decades. The advantages of nursery seedlings are numerous, though one quality in particular makes them favorable over natural regeneration- their initial growing conditions. One critical contributor to the initial growth of these seedlings is fertilization. In white spruce (Picea glauca; A. Voss), fertilized seedlings showed higher levels of nutrient uptake, initial growth, and production of biomass after planting than unfertilized seedlings (McAlister \& Timmer 1998).

Despite the abundant nutrients present in nursery soil, trees form relationships with ectomycorrhizal fungi (EcMF). Ectomycorrhizal fungi have been known to alter the nutrient status of seedlings, and are a well-documented occurrence in nursery settings for many years (Crohgan 1984; Richter \& Bruhn 1993). These fungi often aid in the accumulation of beneficial nutrients such as nitrogen $(\mathrm{N})$, phosphorus $(\mathrm{P})$, magnesium (Mg), and other elements (Smith \& Read 2008). Separately or in combination fertilization and ectomycorrhizal fungi can serve to provide the host seedling with many nutrients that may otherwise be limiting, but all EcMF species are not identical in their effects on plant nutrition.

Whether through intentional or unintentional inoculation, EcMF can be found growing on the roots of many nursery grown plants (Menkis et al 2005). Although many EcMF often experience declines in areas with too high nutrient availability, in particular N (Arnolds 1991; Wallenda \& Kottke 1998), some EcMF are less impacted by such conditions (Lilleskov 2001; Lilleskov 2002; Lilleskov et al. 2012 and references therein). Additionally, the frequent disturbances of the soil associated with nurseries favor pioneer EcMF (Kranabetter 2004; Danielson \& Visser, 1990). The combination of these factors creates favorable growing conditions for common greenhouse species of fungi such as Thelephora terrestris, Amphinema byssoides, and Paxillus involutus (Brunner \& Brodbeck 2001).

The communities present during development in the nursery may be adapted to the high nutrient conditions that constant fertilization provides (Flykt et al. 2008). However, it is unclear whether these fungi are acting as mutualists. It has been 
suggested that under certain conditions, EcMF can actually behave parasitically (Kummel \& Salant 2006; Karst et al 2008; Johnson et al 1997). Therefore, it is important to examine if fungi colonizing seedlings are providing any benefit.

Once the seedling and fungi are moved to the field, the nutrient conditions under which the community exists are highly altered; available inorganic $\mathrm{N}$ and $\mathrm{P}$ decrease (Kranabetter 2004; Danielson \& Visser 1990; and Krasowski, 1999). The process of adaptation has potential implications for both the fungal community and the host. Changes in the dominant EcMF symbionts are likely to occur (Flykt et al 2008). Such a shift carries the potential to alter the types of nutrients being absorbed, the rate at which they are being absorbed, and in what quantity the nutrients are being stored in the host organism (Krasowski 1999), and the carbon cost of nutrient uptake (Smith \& Reed 2008). It may be beneficial for the seedling to accumulate excess nutrients in the nursery setting, in order to ease the transition. However, too high nutrient content may leave seedlings vulnerable to frost damage or insect attack (Holopainen et al 1995).

In order to further examine the potential stoichiometric, growth, and allocation impacts of the EcMF community under fertilized and unfertilized conditions, white spruce seedlings were collected from the Toumey Nursery in Watersmeet, Michigan. The USFS nursery grows many species of trees for planting on federal lands. With this information in mind, we were able to develop four questions for investigation. First, do ectomycorrhizal fungi have an effect on the foliar nutrient concentration of both fertilized and unfertilized Picea glauca seedlings? Similarly, we investigated to see if the ectomycorrhizal fungi have an effect on the foliar nutrient content of both fertilized and unfertilized Picea glauca seedlings? Third, do ectomycorrhizal fungi have an effect on growth and root to shoot ratios of Picea glauca seedlings? Finally, how does fertilization interact with EcMF communities to affect seedling foliar nutrient concentration and content, growth, and root to shoot ratios? 


\section{2- Methods}

\section{1- Sample Collection}

One-year-old white spruce seedlings for this study were collected from the Toumey nursery in Watersmeet, Michigan on the April 29 $9^{\text {th }}, 2011$ (Fig 1.). During their first growing season the seedlings had received a 9-45-15 starter fertilizer, followed by treatment with a high $\mathrm{N}$ fertilizer (Scott's Champion 21-8-18), and finally a 4-25-35 finisher fertilizer. Seedlings were chosen by not only their dominant morphotype, but also in order to equally represent the fungal diversity present on the roots, as evident by fungal mycelium visible at the bottom of the tree tube (Fig 2, 3, \& 4.). The seedlings were brought to the Northern Research Station Forestry Sciences Laboratory in Houghton, Michigan. Seedlings were removed from their original planting containers and given an individual identifier.

Once at the laboratory, EcMF were morphotyped over the next several days under a dissecting microscope. Ectomycorrhizas on the surface of the intact peat plug were morphotyped by rhizomorph presence and type, mantle color and texture, and hyphal anatomy (Agerer 1987 - 2008). This morphotyping was not intended to be exhaustive, but simply to ensure that a diversity of morphotypes could be represented in both of the fertilization treatments.

\section{2- Outplanting}

Once initial morphotyping was completed, 73 trees were repotted in Stuewe and Sons 60 Deepots with $1050 \mathrm{~cm}^{3}$ of pure peat moss (Sunshine Organic Genuine Canadian Sphagnum) added surrounding the original plug. Initial morphotypes were evenly distributed between the treatments. To minimize contamination by airborne fungal spores, the pots were capped with an approximately $2.5 \mathrm{~cm}$ thick layer of fibrous synthetic filler (Poly-Fil 100\% Polyester Fiberfill). Additionally, the outside of the Deepot container rack was covered with insulating foam to keep roots cool. 
The 73 trees were then placed outdoors in full sunlight, and assigned to one of two treatments- fertilized or unfertilized. Fertilized seedlings received an amount of $100 \mathrm{ml}$ of water and fertilizer mix (Scott's Champion 21-8-18, trace elements included [Table 1.]) diluted to achieve $100 \mathrm{ppm}$ of $\mathrm{N}$. This was the same fertilizer and fertilization rate that had been applied at the nursery. Those trees in the "no fertilizer added" category received $100 \mathrm{ml}$ of DI water. Trees were watered every day for the first week of establishment, then as needed for the remainder of the growing season. All watering treatments applied to the fertilization group occurred with the same dilute fertilizer solution.

\section{3- Sample harvest and chemical analysis}

Trees were harvested on October $3^{\text {rd }}, 2011$. Due to logistical limitations, 21 of the original 73 seedlings were processed. Root tip colonization was estimated by using the methods of Giovannetti \& Mosse (1980) with some modifications. Roots were laid on a $1 \mathrm{~cm}$ gridded tray. At every intersection with a root tip, the tip was morphotyped and recorded. This was done for 300 root tips from outside the original peat plug, and 300 root tips from within the original peat plug (See Table 2.). These regions could be easily distinguished morphologically based on peat characteristics and root tracking of container walls. Ten root tips per morphotype were then collected separately from both the old and new roots of the tree for DNA analysis. The root tips were freeze-dried and stored in $1.5 \mathrm{~mL}$ eppendorf tubes. Upon completion of root tip sampling, remaining roots were divided into fine and coarse roots, to be stored for analysis. The stem, foliage, and roots were placed into a $45^{\circ} \mathrm{C}$ oven for drying. Once dry, all tissues were weighed, and the foliage was collected to be ground and analyzed. To determine carbon and $\mathrm{N}$ concentration, $1.5 \mathrm{mg}$ of the ground foliar tissue was weighed out and analyzed by running the sample through an elemental analyzer (Fisons NA1500). An additional $300 \mathrm{mg}$ of foliar tissue was weighed out for analysis for $\mathrm{K}, \mathrm{Ca}, \mathrm{Mg}, \mathrm{Mn}, \mathrm{Fe}, \mathrm{Cu}, \mathrm{B}, \mathrm{Al}, \mathrm{Zn}, \mathrm{Na}$, and $\mathrm{S}$ concentration, which was carried out by the Penn State Agricultural Sciences 
laboratory using acid digestion on an Autoblock digester (Environmental Express, Charleston, SC, USA) and inductively coupled plasma (ICP) analysis (Huang \& Schulte 1985). Elemental content was estimated by multiplying biomass by concentration.

\section{4- DNA Fungal Identification}

To identify the mycorrhizae present on the sample root tips, PCR DNA amplifications were carried out on a subset of the root tips collected from the different morphotypes. Individual root tips were selected from the subset of 10 to undergo DNA extraction. The DNA extraction was done using a REDExtract-N-Amp Plant PCR kit (Sigma-Aldrich Corp., St. Louis, MO, USA). We followed manufacturer's instructions with the following exceptions: root tips were digested in $10 \mu \mathrm{L}$ of extraction solution, and suspended with $10 \mu \mathrm{L}$ of dilution solution.

For DNA amplification, $5.68 \mu \mathrm{L}$ of water was combined with $10 \mu \mathrm{L}$ of the REDExtract-N-Amp PCR Readymix, as well as $0.16 \mu \mathrm{L}$ of primer ITS1F and 0.16 $\mu \mathrm{L}$ of primer ITS4. To this cocktail was added $4 \mu \mathrm{L}$ of the extracted DNA solution. After a brief centrifuge, the samples were then placed in a Mastercycler thermocycler (Eppendorf North America, Hauppague, NY, USA) using program DS35 (Table) 3. Using gel electrophoresis, PCR products were visualized and analyzed for successful PCR amplification. After ethidium bromide staining, bands were imaged using Kodak EDAS 290 (Kodak, Rochester, NY, USA). Those samples displaying single, clearly defined bands of appropriate size were deemed successful, and cleaned according to the protocol laid out in the QIAquick PCR Purification Protocol (Qiagen, Venlo, Netherlands). Samples were washed with buffer PBI at a ratio of 5:1 (buffer:PCR product) in $1.5 \mathrm{ml}$ eppendorf tubes, before being transferred to QIAquick spin columns. These columns were centrifuged for 60 seconds to remove cleaning 
agent, then centrifuged for an additional 30 seconds to remove any residual cleaning material. Samples were then washed in an 8:2 (buffer: 100\% ethanol) buffer PE mix.

Samples were then centrifuged for 30 seconds. Once through flow was discarded, samples were eluted in $50 \mu \mathrm{L}$ of DI $\mathrm{H}_{2} \mathrm{O}$. DNA concentration was determined by placing a $0.5 \mu \mathrm{L}$ sample onto a NanoDrop3300 (Thermo-scientific, Waltham, MA, USA).

Cleaned and quantitated samples were sent to the Nevada Genomics lab of University of Nevada, Reno, for sequencing on an ABI3730 (Applied Biosystems, Foster City, CA, USA). Sequences were then run through DNA BLAST (http://blast.ncbi.nlm.nih.gov/Blast.cgi) for identification.

Two species of Amphinema were common on tree roots. To better understand their relationship to known Amphinema species we developed phylogenetic trees comparing our isolates to previously sequenced Amphinema species. Using Unipro Ugene, DNA sequences were aligned with knowns, and both percent similarity matrices and a neighbor-joining tree generated.

\section{5- Morphological identification}

In a few samples, DNA sequencing was not successful. To identify these samples, other successfully sequenced samples were examined under a microscope. Notes on rhizomorph structure, mantle structure, clamp connections, hyphal anastomoses, and emanating hyphal abundance were taken. These identified standards were then used to morphologically identify the unknown root tips.

\section{6- Statistical analysis}

In order to properly account for the effects of communities present on the white spruce seedlings, multivariate methods were carried out using the $\mathrm{R}$ package vegan (Oksanen et al 2012). Data were first transformed using Wisconsin double 
standardization. Next dissimilarities were calculated using the default Bray's dissimilarity index. Next, these data were ordinated using non-metric multidimensional scaling (NMDS). Once ordinated, EnvFit was used to relate plant

growth and nutritional variables to the NMDS ordination (Oskanen 2013). Biplots were generated to help visualize the comparison. To test the relationship between individual fungal species and specific nutrients, regression analyses were carried out in Sigmaplot 9. These models were often linear, though in some cases, non-linear fits were better. Additionally, Welch's two tailed T-tests were conducted in order to compare fertilized and unfertilized treatments.

\section{3- Results}

\section{1- Fungal community composition}

Results of the DNA analysis revealed three species of fungi on multiple seedlings, as well as two other species that appeared only on a single seedling. Of the three dominant fungi, two species were of the genus Amphinema. The third dominant species was identified as Thelephora terrestris. Of the two Amphinema species, both matched to as yet uncharacterized species. Therefore, the species were given the provisional identifications applied by Kõljalg: Amphinema sp. 1 (sensu Urmas Kõljalg, JN943919.1), and Amphinema sp. 5, (sensu Urmas Kõljalg, JN943909.1) as described in the original DNAblast results.

Amphinema sp. 1, although phylogenetically and morphologically similar to Amphinema byssoides, was identifiable as a unique species at the DNA level (Fig 5). Amphinema sp. 1 is characterized by a plectenchymatous mantle with many emanating hyphae ([Fig 6.]). Hyphae are covered by small protuberences, giving the hyphae a warty appearance (Fig 7.). H anastomoses act as connections between the emanating hyphae (Fig 8.). Clamp connections were present. Additionally, somewhat loose rhizomorphs are sometimes present (Fig 9.). 
Amphinema sp. 5 is relatively distinct from Amphinema sp. 1. As with Amphinema sp. 1, the mantle is plectenchymatous and is characterized by loose emanating hyphae (Agerer 1987 [Fig 10.]). However, the hyphae of Amphinema sp. 5 are smooth. $\mathrm{H}$ anastomoses are also present acting as connections between the hyphae (Fig 11.). Clamp connections were present. Rhizomorphs were not observed.

Thelephora terrestris was readily identifiable, due both to its strong DNA matches, as well as distinct morphotype (Agerer 1987). The mantle of the fungus was tight to the root tip with few to no emanating hyphae (Fig 12.). Cystidia were clear visible extending from the mantle (Fig 13.). Clamp connections were present. Rhizomorphs were well organized into tight bundles (Fig 14.).

Two additional types of mycorrhizal fungi were also found to be growing on single seedlings within the sample group. Boletus variipes is a basidiomycete and the fungus is more commonly associated with the family Quercus. The second species was identified as the ascomycete Sphaerosporella brunnea, which is commonly found as EcMF in greenhouses and known to associate with evergreen species (Danielson 1984).

\section{2- Foliar chemistry}

The effects of fertilization on the white spruce foliar nutrients were clearly evident (Table 4.). As one might expect, the mean concentration of nutrients were higher in all cases except for $\mathrm{Na}$ and $\mathrm{K}$ (Fig $15 \& 16$.). The most notable difference between treatments in the plant chemistry was in foliar $\mathrm{N}$, which was the only element to show a statistically significant difference between the two treatments ( $p$ value $<0.0001)$. $\mathrm{N}$ was present in the fertilized trees compared to unfertilized at a ratio of 2.84:1.P showed a marginally significant positive effect of fertilization ( $\mathrm{p}$ value $=0.051)$. 


\section{3- Fungal community effects on foliar nutrient concentration (NMDS)}

The fungal community, as a whole, caused significant changes amongst the

nutrient statuses of the seedlings (Fig $17 \&$ 18). NMDS analysis revealed that in the unfertilized seedlings, the fungal community affected foliar concentrations of $\mathrm{N}$ $\left(\mathrm{R}^{2}=0.56, \mathrm{p}=0.03\right)$, with a marginal effect on $\mathrm{K}\left(\mathrm{R}^{2}=0.47, \mathrm{p}=0.08\right)$. Results of nutrient analysis of the fertilized seedlings revealed significant fungal community effects on $\operatorname{Mg}\left(R^{2}=0.57, p=0.04\right), \operatorname{Mn}\left(R^{2}=0.80, p=0.003\right)$, and $B\left(R^{2}=0.80, p=0.003\right)$, with marginally significant changes to $P\left(R^{2}=0.50, p=0.08\right), C a\left(R^{2}=0.50, p=0.09\right)$, $\mathrm{S}\left(\mathrm{R}^{2}=0.53, \mathrm{p}=0.08\right), \mathrm{Cu}\left(\mathrm{R}^{2}=0.54, \mathrm{p}=0.07\right)$, and $\mathrm{Zn}\left(\mathrm{R}^{2}=0.58, \mathrm{p}=0.05\right)$.

\section{4- Fungal species effects on foliar nutrient concentration}

Individual fungal species differed in their correlation with many nutrients in both unfertilized and unfertilized seedlings. Regressions indicated unfertilized seedling $\mathrm{N}$ concentration was significantly negatively related to abundance of Amphinema sp. $1\left(\mathrm{R}^{2}=0.57\right.$, $\mathrm{p}=0.01$ [Fig 19.]).

In fertilized seedlings Amphinema sp. 1 and T. terrestris demonstrated opposite trends. In contrast with the unfertilized treatments, Amphinema sp. 1 positively affected many nutrient concentrations. Amphinema sp. 1 was positively correlated with $\mathrm{P}$ concentration $\left(\mathrm{R}^{2}=0.52, \mathrm{p}=0.07\right.$ [Fig 20.]), $\mathrm{B}\left(\mathrm{R}^{2}=0.44, \mathrm{p}=0.03\right.$ [Fig 21.]), $\mathrm{Mg}\left(\mathrm{R}^{2}=0.56, \mathrm{p}=0.01\right.$ [Fig 22.]), and $\mathrm{Mn}\left(\mathrm{R}^{2}=0.78, \mathrm{p}=0.0006\right.$ [Fig 23.]). The concentration of these nutrients well surpassed those in the seedlings with high numbers of non-mycorrhizal tips.

In fertilized seedlings $T$. terrestris was associated with generally nonsignificant negative trends, and a significant negative correlation with $\mathrm{P}\left(\mathrm{R}^{2}=0.54\right.$, $\mathrm{p}=0.01$ [Fig 20.]). At high T. terrestris abundance, concentrations of $\mathrm{P}$ were observed to be even less than those in seedling with high numbers of non-mycorrhizal tips.

While Amphinema sp. 5 was present in both treatments, there were an insufficient number of samples to draw strong conclusions about the effects of that 
species on foliar chemistry. However, a potential strong decrease in B and $\mathrm{Mg}$ was seen in fertilized seedlings.

Ratios of all the elements in the different fertilization treatments were calculated (Table 6). To understand EcMF effects on stoichiometry, we examined species effects on $\mathrm{N}$ to $\mathrm{P}$ ratios. In unfertilized seedlings, Amphinema sp. 1 demonstrated a strong negative trend $\left(\mathrm{R}^{2}=0.90, \mathrm{p}=0.0002\right.$ [Fig 24.]). Amphinema sp. 5 and $T$. terrestris both demonstrated marginally significant positive trendsAmphinema sp. $5\left(\mathrm{R}^{2}=0.52, \mathrm{p}=0.10\right)$, T. terrestris $\left(\mathrm{R}^{2}=0.54, \mathrm{p}=0.09\right.$ [Fig 24.]). No significant trends were observed in fertilized seedlings (Fig. 25). No significance tests could be performed for the effect of Boletus variipes and Sphaerosporella brunnea, as each of these species was only present on one unfertilized seedling.

\section{5- Fungal community effects on foliar nutrient content (NMDS)}

When examining the NMDS results for the fungal community's effect on nutrient content, few significant trends emerged (Fig $26 \& 27$.). In unfertilized trees, a significant trend was observed in $K$ content $\left(R^{2}=0.54, p=0.05\right)$. Additionally, a marginally significant trend was observed in $\mathrm{P}$ content $\left(\mathrm{R}^{2}=0.54, \mathrm{p}=0.06\right)$. In fertilized seedlings, no significant trend was observed. However, two marginally significant trends were observed; one in $\mathrm{Mn}\left(\mathrm{R}^{2}=0.50, \mathrm{p}=0.07\right)$ and one in $\mathrm{Cu}\left(\mathrm{R}^{2}=\right.$ $0.54, \mathrm{p}=0.099)$.

\section{6- Fungal species effects on foliar nutrient content}

The greatest species effect on nutrient content can be observed in fertilized seedlings, within Amphinema sp. 1, which showed a significant positive effect on B $\left(\mathrm{R}^{2}=0.44, \mathrm{p}=0.04\right.$ [Fig 28.]), and $\mathrm{Mn}\left(\mathrm{R}^{2}=0.62, \mathrm{p}=0.01\right.$ [Fig 29.]). Additionally, in the fertilized treatment a strongly negative relationship was observed between $\mathrm{Mg}$

content and number of non-mycorrhizal root tips $\left(\mathrm{R}^{2}=0.42, \mathrm{p}=0.04\right.$ [Fig 30.]). 
For unfertilized seedlings, only $\mathrm{P}$ was significantly affected, exhibiting a strongly positive relationship with abundance of Amphinema sp. $1\left(\mathrm{R}^{2}=0.75\right.$, $\mathrm{p}=0.0006$ [Fig 31.]) and a strong negative relationship with abundance of Amphinema sp. $5\left(\mathrm{R}^{2}=0.40, \mathrm{p}=0.03\right.$ [Fig 31.]). Although $\mathrm{K}$ was found to be significant in the

NMDS, no significant species effects were found.

\section{7- Treatment effects on biomass and root:shoot ratios}

As with foliar chemistry, fertilization treatment affected overall growth and root to shoot ratios. Those seedlings receiving fertilization had higher mean above ground biomass, higher mean below ground biomass, and a higher mean root to shoot ratio than those unfertilized seedlings (Table 6).

\section{8- Community effects on biomass and root:shoot ratios (NMDS)}

To determine effects of fungal community on foliar biomass, stem biomass, below ground biomass, total biomass, and root:shoot ratio, NMDS was conducted (Fig 32 \& 33). No significant trends were observed in unfertilized. A marginally significant relationship was observed in fertilized seedlings only for root:shoot ratio $\left(\mathrm{R}^{2}=0.52, \mathrm{p}=0.06\right)$.

\section{9- Fungal species effects on root:shoot ratios.}

To understand the origin of the community effect on root:shoot ratios we examined species-level effects. In the unfertilized treatment, there were no significant trends associated with individual species of fungus for root:shoot ratio (Fig 34.). Within the fertilized treatments, non-mycorrhizal tips demonstrated a strong positive relationship to root:shoot ratio $\left(\mathrm{R}^{2}=0.82, \mathrm{p}<0.001\right.$ [Fig 35.]). 


\section{4- Discussion}

\section{1- Individual species effects on seedling chemistry and stoichiometry}

When examining growth limiting nutrients, the trends were intuitive (Table 7 $\& 8)$. $\mathrm{N}$ was the common limiting nutrient in unfertilized seedlings. The average concentration for $\mathrm{N}$ in these trees was $6 \mathrm{~g} / \mathrm{kg}$, well below the estimated threshold value for deficiency of $10.5 \mathrm{~g} / \mathrm{kg}$ (Binkley \& Fisher 2013). In fertilized seedlings, growth limiting nutrients were not an issue. All macronutrients and micronutrients for which we had threshold data were found in non-limiting concentrations (Binkley \& Fisher 2013; Lehto et al 2010; Polle et al, 1992). It should also be noted that the micronutrients in the fertilized seedlings were present in higher mean concentrations that those in unfertilized seedlings

Nutrient ratios in the seedlings also responded to fertilization treatment (See Table 4). $\mathrm{N}$ was present in much higher ratios in fertilized seedlings than in unfertilized. $\mathrm{P}$ and $\mathrm{K}$, though macronutrients also present in the fertilizer, were much more variable. Possibly the most interesting comparisons was the ratios of $\mathrm{N}: \mathrm{P}$ in unfertilized treatments. In fertilized treatments, the N:P ratio was fairly balanced (mean-9.38:1). However, in unfertilized seedlings this ratio was considerably lower (4.14:1). Interestingly, all fungal species exhibited both significant and marginally significant trends. In Amphinema sp. 1, the trend was strongly negative, suggesting that the availability of $\mathrm{N}$ in the peat substrate is extremely low, or all the EcMF are keeping the $\mathrm{N}$ for their own processes. It should also be noted there was considerable variability in the concentrations of micronutrients in the seedlings.

One of the more interesting components of this experiment is the interaction of individual EcMF with fertilization (Table 7.). In unfertilized treatments Amphinema sp. 5 and T. terrestris showed signs of positive trends in their effect on $\mathrm{N}$ concentration. This may suggest that Amphinema sp. 5 and T. terrestris' primary contribution to the host is the supply of N. However, when examining foliar content, these species display weak negative trends. This may potentially be an indicator that 
the fungi are not actually providing the tree with increased $\mathrm{N}$, but instead reducing the concentration of available nutrients. This may in turn impact the overall growth of the seedling, as the nutrients needed to support valuable cellular components may be less available.

When examining Amphinema sp. 5 and T. terrestris impacts in fertilized seedlings, a different trend is noticed. Increased presence of Amphinema sp. 5 and T. terrestris lead to general decreases in nutrient concentration. This trend is very noticeable in the effect of $T$. terrestris on the concentration of $\mathrm{P}$ in fertilized seedlings. The decrease in $\mathrm{P}$ concentration is accompanied by no change in the $\mathrm{P}$ content of the seedlings. This relationship suggests that although the concentration of $\mathrm{P}$ is decreasing in the seedlings, $\mathrm{P}$ is still likely being supplied in level sufficient to continue development of $\mathrm{P}$ containing plant structures.

These trends give us valuable insight to the functionality of T.terrestris. Many past studies have revealed that $T$. terrestris is more tolerant of high $\mathrm{N}$ sites (Lilleskov et al 2002b; Chalot \& Brun 1998; Arnolds 1991). However, the data suggests that $T$. terrestris contributes the most under low $\mathrm{N}$ conditions. This relationship between $T$. terrestris and the study seedlings suggest that $T$. terrestris may actually be a poor symbiotic partner under high $\mathrm{N}$ conditions, and not make significant positive or negative contributions under low $\mathrm{N}$ conditions, due to it's minimalistic contributions to the host seedling (Johnson et al 1997).

Amphinema sp. 1 displayed trends quite different from those observed in Amphinema sp. 5 and T.terrestris. Amphinema sp. 1 demonstrated a significant ability to beneficially supply $\mathrm{P}, \mathrm{B}$, and other valuable nutrients to host seedlings receiving fertilization. Especially interesting was an increase in the concentration of $\mathrm{Mg}$ in fertilized seedlings. Mg is critical for photosynthesis. Previous studies have tied Mg concentration to increased photosynthetic C gain (Ericsson \& Kähr 1995). Therefore, one might speculate that Amphinema sp. 1 supplies $\mathrm{Mg}$ in elevated quantities to receive more $\mathrm{C}$ compounds from the host seedling. In unfertilized seedlings, Amphinema sp. 1 was tied to a decrease in concentration of foliar $\mathrm{N}$, as well as a decrease in N:P ratio. Amphinema sp. 1's lack of N supply may in fact alter 
biomass production. This would be expected to stimulate belowground $\mathrm{C}$ allocation. Additionally, the increase in Mg may also help to boost the levels of carbon being sent to the fungus. It is possible that in unfertilized plants, Amphinema sp. 1 is a poor mutualist, not supplying the nutrients needed to grow under those conditions.

However, when one looks at the general effects of Amphinema sp. 1, total biomass is positively affected. Additionally, content of $\mathrm{N}$ is not decreased significantly, while $\mathrm{P}$ is significantly increased. It appears that Amphinema sp. 1 is not negatively affecting the overall content of $\mathrm{N}$ within the host plant, but instead boosting the levels of other nutrients and hence diluting the $\mathrm{N}$ pool.

In addition to the differences in concentration between the fungal species in each treatment, some differences also exist in the total content of the foliage. Interestingly, concentration and content of nutrients in seedlings do not necessarily coincide with one another. In unfertilized treatments, no significant differences existed between any fungal species.

Ectomycorrhizas on fertilized seedlings affected content of some nutrients. Those seedlings with elevated counts of Amphinema sp. 1 demonstrated increased content of B. There has been uncertainty as to the purpose of this micronutrient in plants (Blevins \& Lukaszweski 1994; Bolaños et al 2004). It is hypothesized that B may play a role in plant cell membranes (Blevins \& Lukaszewski 1998; Lehto et al 2010). Relevant to the present study, it has been shown that B fertilization leads to increased EcMF colonization (Mitchell et al 1987; Lehto et al 2004; Lehto et al 2010). This increase in EcMF could heighten the ability of plants to secure more critical limiting nutrients. Thus overcoming B limitation is clearly beneficial to both host and EcMF.

Amphinema sp. 1 also produces a similar increase in Mn content. Mn has been shown to be a critical component of chloroplasts, specifically benefiting photosystem II (Teichler-Zallen 1969). It is possible that EcMF may increase the supply of Mn in order to boost the supply of carbon compounds. 


\section{2- Individual species effects on plant biomass and allocation}

Despite having obvious effects on plant nutrition, effects on plant biomass and root:shoot allocation were much less pronounced. No significant differences were observed between biomass as a function of EcMF species. Additionally, there were no significant effects of EcMF species on root:shoot ratio. These trends suggest that any differences between the seedlings were caused by the fertilization treatment and presence of ectomycorrhizal fungi, not the particular fungus.

When examining the effects of the EcMF on both treatments, it is uncommon for the nutrient concentration in the leaf tissue to vary in seedlings not supporting EcMF (Ericsson \& Kähr 1995). In the experimental seedlings, a diverse range of foliar concentrations were observed. Despite the variety of foliar nutrient concentrations in the seedlings, there were no significant differences in above ground biomass amongst seedlings in the same treatment.

However, one significant difference was seen in root: shoot ratio. Not surprisingly, there was a significant positive correlation between root:shoot ratio and abundance of non-mycorrhizal root tips. As the seedling does not have a large surface area created by mycorrhiza, it must increase its total root area. This corresponds with evidence that EcMF aid in expansion of surface area for nutrient uptake (Smith \& Read 2008). However, an alternative explanation for the change in ratio may be that when not supporting EcMF, the carbon that was supporting the fungus may then be available for root production.

\subsection{Practical applications of fungi in field versus nursery settings}

In the past, many studies have been conducted to determine the effects of EcMF on nursery grown seedlings. Many of these studies have examined the effects of EcMF directly in the nursery, or immediately after out-planting (Rudawska et al 2006; Rincón et al 2005; Quoreshi \& Timmer 1998; Trappe 1977). In these studies, T. terrestris is commonly considered a green-house parasite (Trappe 1977; Quoreshi 
\& Timmer 1998). T.terrestris has been shown to inhibit growth in inoculated seedlings in both nursery and out planted settings (Trappe 1997). In this study, no significant trends affecting growth could be attributed to abundance of $T$. terrestris. However, some conclusions may be able to be drawn based on T.terrestris' nutrient contributions. In fertilized settings, T. terrestris demonstrated significant negative trends in concentration of both $\mathrm{P}$ and $\mathrm{Mn}$. This reduction limits pools of essential nutrients for future growth. Additionally, in unfertilized seedlings, no significant trends were observed, either positive or negatively, in all aspects of plant growth and nutrient concentration. Based on this observation, we can draw no strong conclusions as to the fungus' contributions in this environment.

Amphinema sp. 1 and Amphinema sp. 5 have no literature on effects of host nutrition or growth relating to their species. However, as this paper has shown, various species of Amphinema are often lumped under A. byssoides. As we have demonstrated, this may be problematic since species of Amphinema appear to behave differently under similar nutrient conditions. Still, while examining the data, it is possible to formulate some possible hypotheses as to the benefit and function of these fungi.

Amphinema sp. 1 appears largely to be a mutualist in both fertilized and unfertilized conditions. Positive trends are seen in fertilized treatments for above ground biomass, as well as in unfertilized treatments for total biomass. In addition, Amphinema sp. 1 demonstrates an ability to increase both concentration and content in its host seedling ( $\mathrm{N}$ concentration being the exception). This increase in nutrient supply allows Amphinema sp. 1 to boost the potential growth of its host, making it a favorable mutualist.

Although we must be cautious given the low sample number, the effects of Amphinema sp. 5 on seedlings were in stark contrast to those of Amphinema sp. 1. Amphinema sp. 5 not only was associated with trends for decreasing concentration of most nutrients in both fertilized and unfertilized treatments, but also decreasing content in unfertilized seedlings. These trends are reflected in seedling growth, where aboveground biomass and total biomass exhibited negative trends in unfertilized 
seedlings colonized by Amphinema sp. 5. Clearly this species requires greater study as a potentially strong conditional parasite under unfertilized conditions.

\section{5- Conclusions}

Molecular methods allowed us to distinguish the species of fungi colonizing nursery seedlings, including two unidentified species of Amphinema with apparently divergent effects on seedling nutrition under varying fertilization regimes. This is the first time that these species have been identified as nursery colonists, having

previously been lumped under the closely related A. byssoides. Furthermore, our statistical approach allowed us to test for community and species effects on plant nutrition in a more realistic multispecies community setting. In the nursery setting, where seedlings are in high nutrient environments, Amphinema sp. 1 proves to be an efficient mutualist, elevating the concentration and content of many macronutrients and micronutrients. This potentially allows for the seedlings to shift $\mathrm{C}$ usage from below-ground growth to above-ground production. In the field, Amphinema sp. 1 continues to show mutualistic qualities.

Both Amphinema sp. 5 and T. terrestris demonstrate strong contrasts to Amphinema sp. 1, acting more parasitically in both conditions. These EcMF are often associated with negative or neutral trends in concentration, content, and elements of growth, which are detrimental for development of the seedling. Still more detrimental, for Amphinema sp. 5 the negative effects of the ectomycorrhizae seem to be most noticeable in unfertilized seedlings. By reducing the nutrient content in seedlings in both the fertilized and unfertilized setting Amphinema sp. 5 and $T$. terrestris demonstrate very little mutualism. It is in the best interest of the nurseries to reduce the abundance of these species in order to promote growth of their seedlings. 


\section{6- References}

Agerer, R. 1987-2008. Color Atlas of Ectomycorrhizae. Einhorn-Verlag. Schwäbisch-Gmünd, Germany.

Arnolds, E. 1991. Decline of Ectomycorrhizal Fungi in Europe. Agriculture, ecosystems, and Environment. Vol. 35(2-3), PP. 209-244

Binkley, D. and Fisher, R. 2013. Ecology and Management of Forest Soils, fourth edition. Wiley-Blackwell Inc. New York City, NY, USA.

Blevins, D. and Lukaszewski, K. 1994. Proposed Physiologic Functions of Boron in Plants Pertinent to Animal and Human Metabolism. Environmental Health Perspective. Vol. 102(7), PP. 31-33.

Blevins, D. and Lukaszewski, K. 1998. Boron in Plant Structure and Function. Annual Review of Plant Physiology and Plant Molecular biology. Vol. 49, PP. 481500

Bolaños, L., Lukaszewski, K., Bonilla, I, and Blevins, D. 2004. Why Boron? Journal of Plant Physiology and Biochemistry. Vol. 42(11), PP. 907-912.

Chalot , M. and Brun, A. 1998. Physiology of Organic Nitrogen Acquisition by Ectomycorrhizal Fungi and Ectomycorrhizas. Microbiology Reviews. Vol. 22, PP. $21-44$

Crohgan, C. 1984. Survey for Mycorrhizal Fungi in Lake States Tree Nurseries. Mycologia. Vol. 76(5), PP. 951-953

Danielson, R. 1984. Ectomycorrhiza Formation by the Opercualte Discomycete Sphaerosporella brunnea (Pezizales). Mycologia. Vol. 76(3), PP. 454-461.

Danielson, R. and Visser, S. 1990. The Mycorrhizal and Nodulation Status of Container-grown Trees and Shrubs Reared in Commercial Nurseries. Canadian Journal of Forest Research. Vol 20, PP. 609-614.

Ericsson, T., and Kähr, M. 1995. Growth and Nutrition of Birch Seedlings at Varied Relative Addition Rates of Magnesium. Tree Physiology. Vol. 15, PP. 85-93.

Flykt, E., Timonen, S., and Pennanen, T. 2008. Variation of Ectomycorrhizal Colonization in Norway Spruce Seedlings in Finnish Forest Nurseries. Silva Fennica. Vol. 42(4), PP. 571-585.

Hoeksema, J. 2010. Ongoing Coevolution in Mycorrhizal Interactions. New Phytologist. Vol. 187, PP. 286-300. 
Holopainen, J., Rikala, R., Kainulainen, P. and Oksanen, J. Resource partitioning to growth, storage, and defence in nitrogen-fertilized Scots pine and susceptibility of seedlings to the tarnish plant bug Lygus rugulipennis. New Phytologist. Vol. 131(4), PP. 521-532.

Huang, C., and Schulte, E. 1985. Digestion of Plant Tissue for Analysis by ICP Emission Spectroscopy. Communications in Soil Science \& Plant Analysis, Vol. 16(9), PP. 943-958.

Johnson, N., Graham, J., and Smith, F. 1997. Functioning of Mycorrhizal Associations Along the Mutualism-Parasitism Continuum. New Phytology. Vol. 135, PP. 575-585

Karst, J., Marczak, L., Jones, M., and Turkington, R. 2008. The MutualismParasitism Continuum in Ectomycorrhizas: A Quantitative Assessment Using Metaanalysis. Ecology. Vol. 89(4), PP. 1032-1042.

Kranabetter, J. 2004. Ectomycorrhizal Community Effects on Hybrid Spruce Seedling Growth and Nutrition in Clearcuts. Canadian Journal of Botany. Vol. 82, PP. 983-991

Krasowski, M., Owens, J., Tackaberry, L., and Massicotte, H. 1999. Above- and Below-ground Growth of White Spruce Seedlings with Roots Divided into Different Substrates with or without Controlled-release Fertilizer. Plant and Soil. Vol. 217, PP. 131-143.

Kummel, M. and Salant, S. 2006. The Economics of Mutualisms: Optimal Utilization of Mycorrhizal Mutualistic Partners by Plants. Ecology. Vol. 87(4). PP. 892-902.

Lehto, T., Lavola, A., Kallio, E., and Aphalo, P. 2004. Boron Uptake by Ectomycorrhizas of Silver Birch. Mycorrhiza. Vol. 14, PP. 209-212.

Lehto, T., Ruuhola, T., and Dell, B. 2010. Boron in Forest Trees and Forest Ecosystems. Forest Ecology and Management. Vol. 260, PP. 2053-2069.

Lilleskov, E., Fahey, T., Horton, T., and Lovett, J. 2002b. Belowground Ectomycorrhizal Fungal Community Change Over a Nitrogen Deposition Gradient in Alaska. Ecology. Vol. 83(1), PP. 104-115.

Lilleskov, E, Fahey, T., and Lovett, G. 2001. Ectomycorrhizal Fungal Aboveground Community Change Over an Atmospheric Nitrogen Deposition Gradient. Ecological Applications. Vol. 11(2), PP. 397-410.

Lilleskov, E., Hobbie, E., and Fahey, T. 2002a. Ectomycorrhizal Fungal Taxa Differing in Response to Nitrogen Deposition also Differ in Pure Culture Organic 
Nitrogen Use and Natural Abundance of Nitrogen Isotopes. New Phytologist. Vol. 154(1), PP. 219-231.

McAlister, J. A., and Timmer, V.R. 1998. Nutrient Enrichment of White Spruce Seedlings During Nursery Culture and Initial Plantation Establishment.

Journal of Tree Physiology. Vol. 18, PP. 196-202.

Menkis, A., Vasiliauskas, R., Tayler, A., Stenlid, J., and Finlay, R. 2005. Fungal Communities in Mycorrhizal Roots of Conifer Seedlings in Forest Nurseries Under Different Cultivation Systems Assessed by Morphotyping, Direct Sequencing, and Mycelial Isolation. Mycorrhiza. Vol. 13, PP. 33-41.

Mitchell, R., Garrett, H., Cox, G., Atalay, A., and Dixon, R. 1987. Boron Fertilization, Ectomycorrhizal Colonization, and the Growth of Pinus echinata Seedlings. Canadian Journal of Forest Research. Vol. 17, PP. 1153-1156.

Oskanen, J. 2013. Multivariate Analysis of Ecological Communities in R: vegan Tutorial. Oulu Yliopisto, Oulu, Finland. Available: http://cc.oulu.fi/ jarioksa/opetus/metodi/vegantutor.pdf

Oksanen, J., Blanchet, F., Kindt, R., Legendre, P., Minchin, P., O’Hara, R., Simpson, G., Solymos, M., Stevens, H., and Wagner, H. 2012. vegan: Community Ecology Package. R package version 2.0-3. Available: http://CRAN.Rproject.org/package=vegan

Polle, A., Chakrabarti, K., Chakrabarti, S., Seifert, F., Schramel, P., and Rennenberg, H. 1992. Antioxidants and Manganese Deficiency in Needles of Norway Spruce (Picea abies) tress. Plant Physiology. Vol. 99, PP. 1084-1089.

Quoreshi, A. and Timmer, V. 1997. Exponential Fertilization Increases Nutrient Uptake and Ectomycorrhizal Development of Black Spruce Seedlings. Canadian Journal of Forest Resources. Vol. 28, PP. 674-682.

Richter, D. and Bruhn, J. 1993. Mycorrhizal Fungus Colonization of Pinus resinosa Transplanted on Northern Hardwood Clearcuts. Soil Biology and Biochemistry. Vol. 25(3), PP. 355-369

Rincón, A., Parladé, J., and Pera, J. 2005. Effects of Ectomycorrhizal Inoculation and the Type of Substrate on Mycorrhization, Growth, and Nutrition of Containerized Pinus pinea L. Seedlings Produced in a Commercial Nursery. Annual Forest Science review. Vol. 63, PP. 1-6.

Rudawska, M., Leski, T., Trocha, L., and Gornowicz, R. 2006. Ectomycorrhizal Status of Norway Spruce Seedlings from Bare-root Nurseries. Forest Ecology and Management. Vol. 236, PP. 375-384. 
Smith, S., and Read, D. 2008. Mycorrhizal Symbiosis: Third edition. Elsevier Ltd. New York City, NY, USA.

Stone, E. 1990. Boron Deficiency and Excess in Forest Trees: A review. Forest Ecology and Management. Vol. 37, PP. 49-75.

Teichler-Zallen, D. 1969. The Effects of Manganese on Chloroplast Structure and Photosynthetic Ability of Chlamydomonas reinhardi. Plant physiology. Vol. 44, PP. 701-710.

Trappe, J. 1977. Selection of Fungi for Ectomycorrhizal Inoculation in Nurseries. Vol. 15, PP. 203-222.

Trocha, L., Rudawska, M., Leski, T., and Dabet, M. 2006. Genetic Diversity of Naturally Established Ectomycorrhizal Fungi on Norway Spruce Seedlings Under Nursery Conditions. Microbial Ecology. Vol. 52, PP. 418-425.

Wallenda, T., and Kottke, I. 1998. Nitrogen Deposition and Ectomycorrhizas. New Phytologist. Vol. 139, PP. 169-187. 


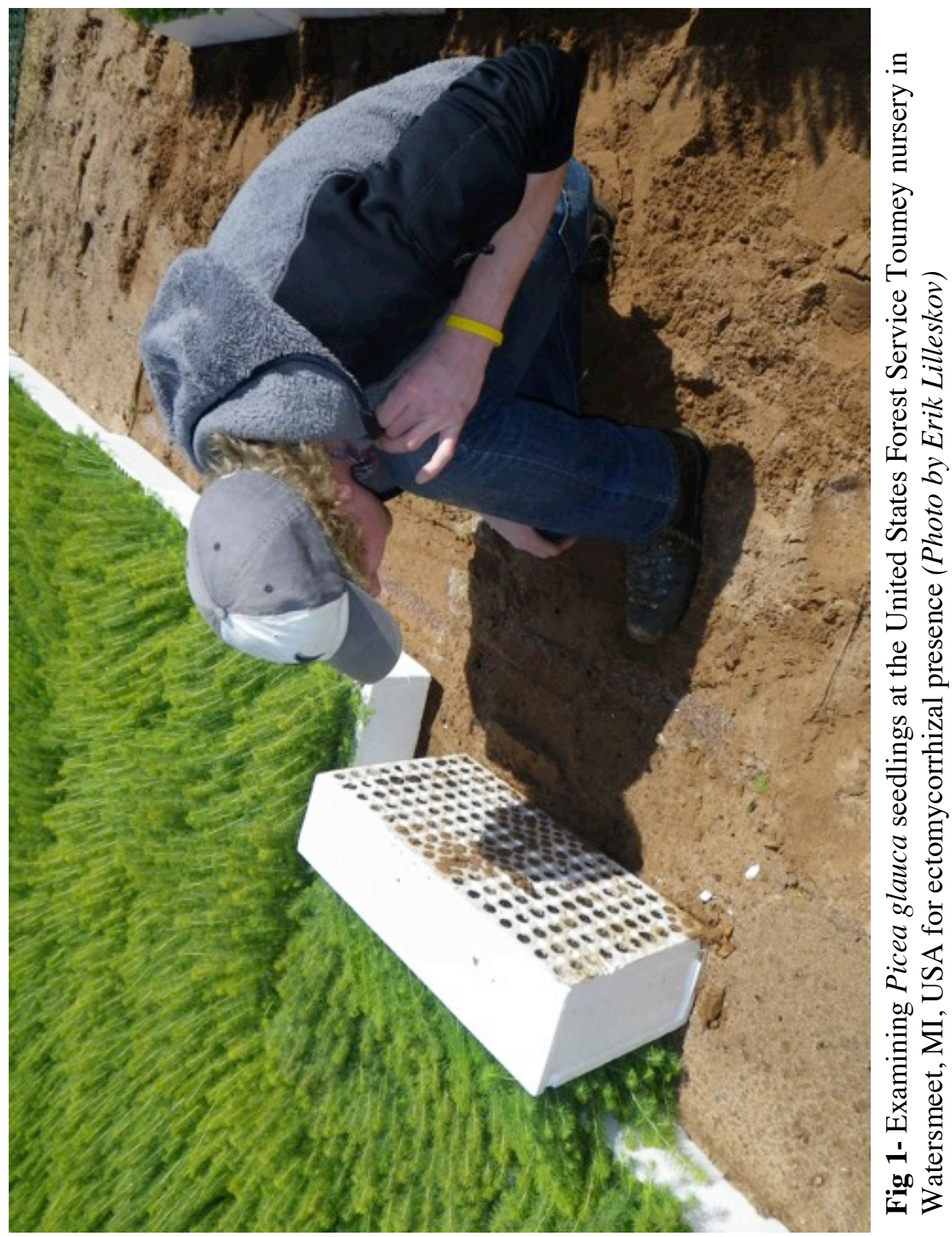




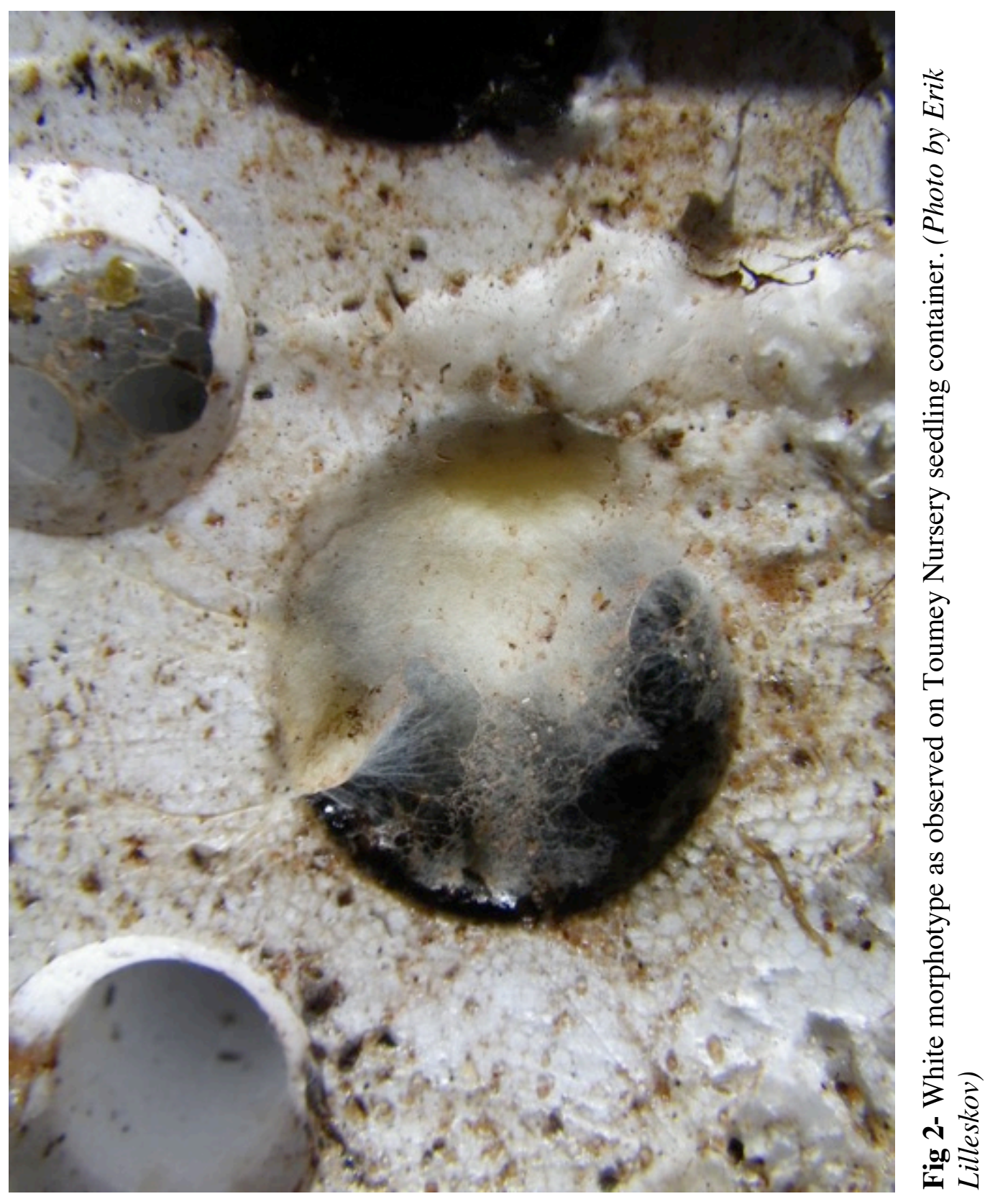




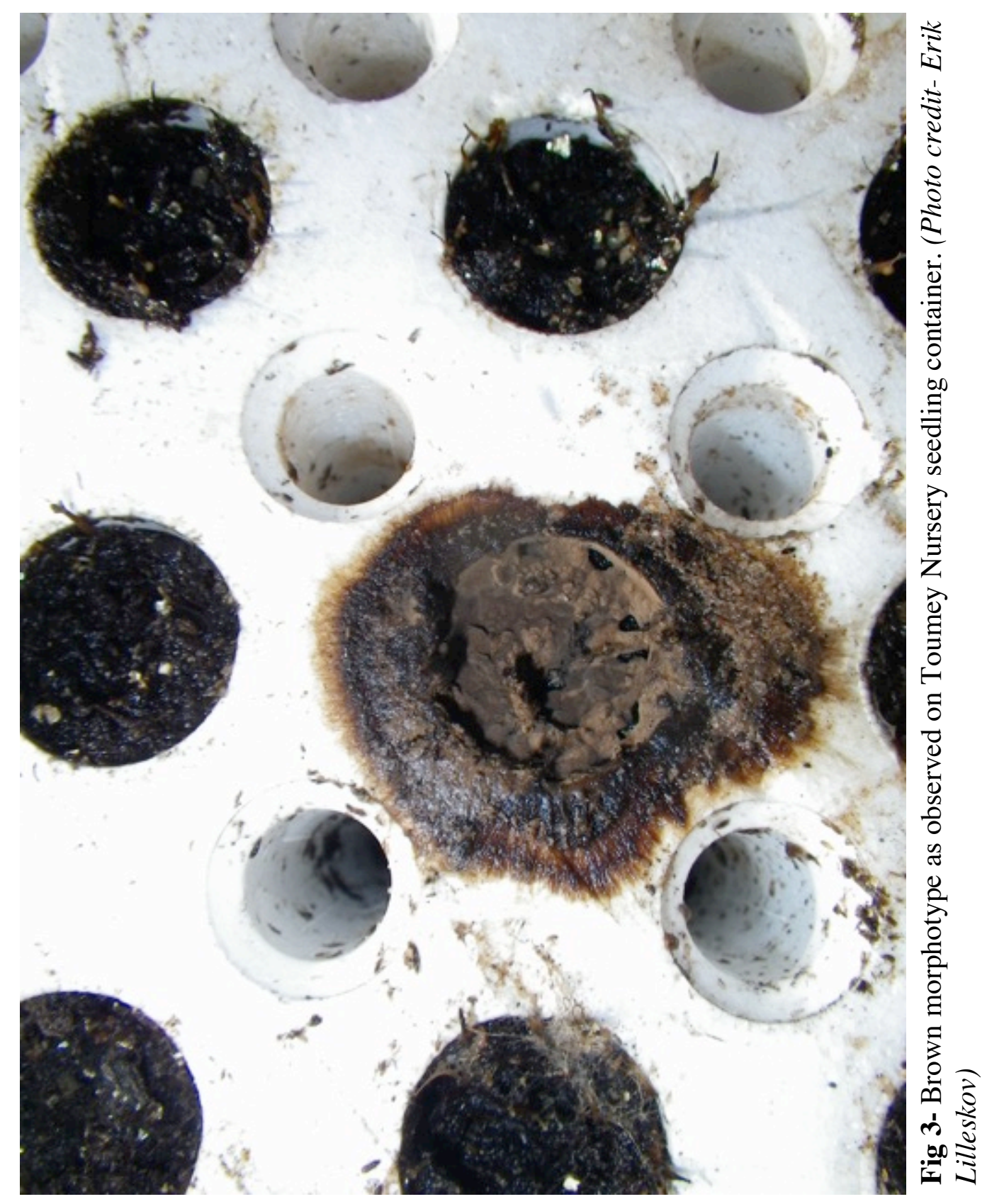




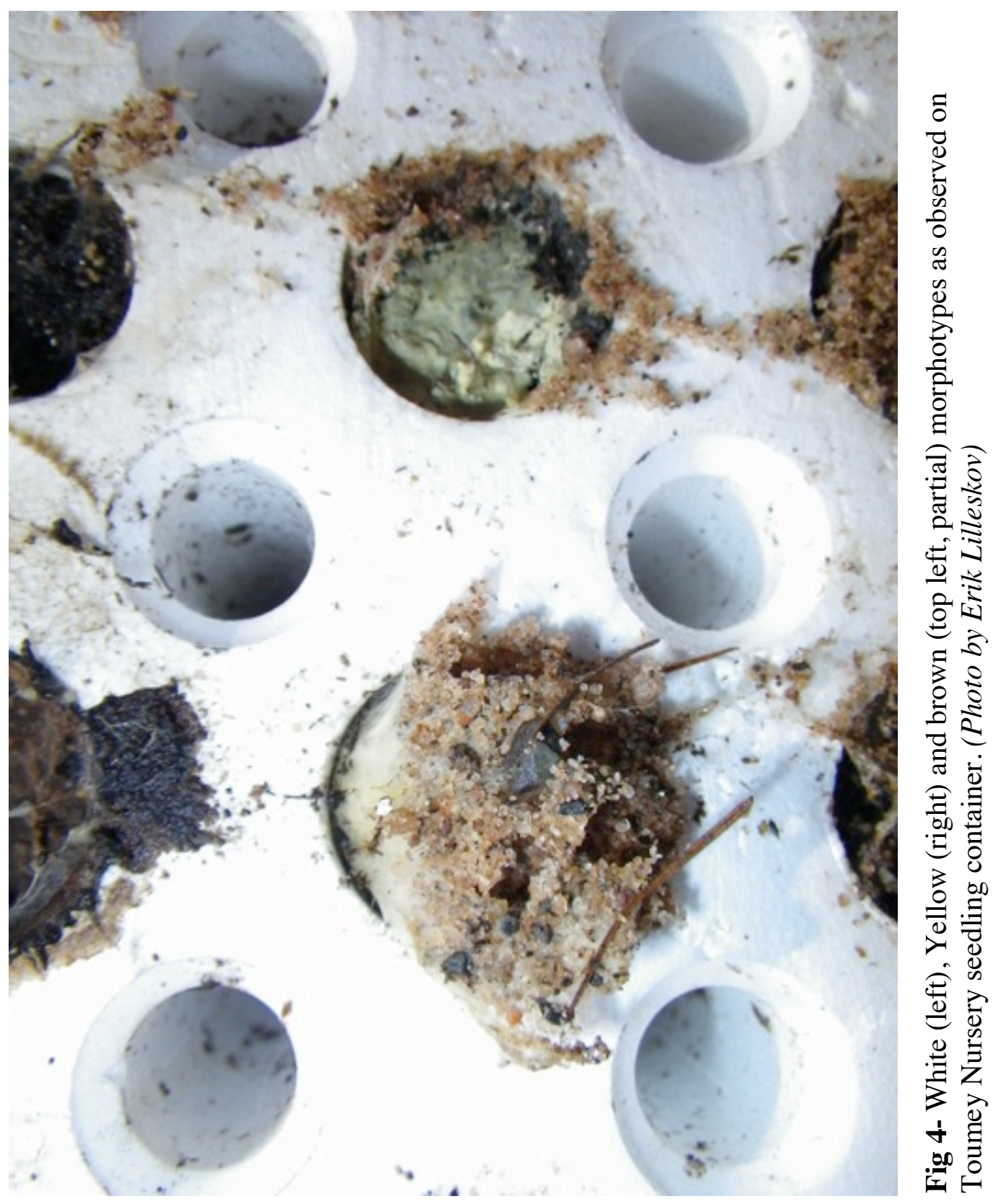


Table 1.- Scott's Champion fertilizer

\begin{tabular}{llc} 
& & Concentration \\
\hline Nitrogen & (Ammonium N) & $8.70 \%$ \\
& (Nitrate N) & $12.30 \%$ \\
Phosphorus & (Phosphate) & $8.00 \%$ \\
& (Soluable & \\
Potassium & potash) & $18.00 \%$ \\
Magnesium & (Water soluble) & $0.15 \%$ \\
Boron & & $0.0262 \%$ \\
Copper & (Water soluble) & $0.0262 \%$ \\
Iron & (Chelated) & $0.1050 \%$ \\
Manganese & (Water soluble) & $0.0105 \%$ \\
Molybdenum & (Water soluble) & $0.0525 \%$
\end{tabular}




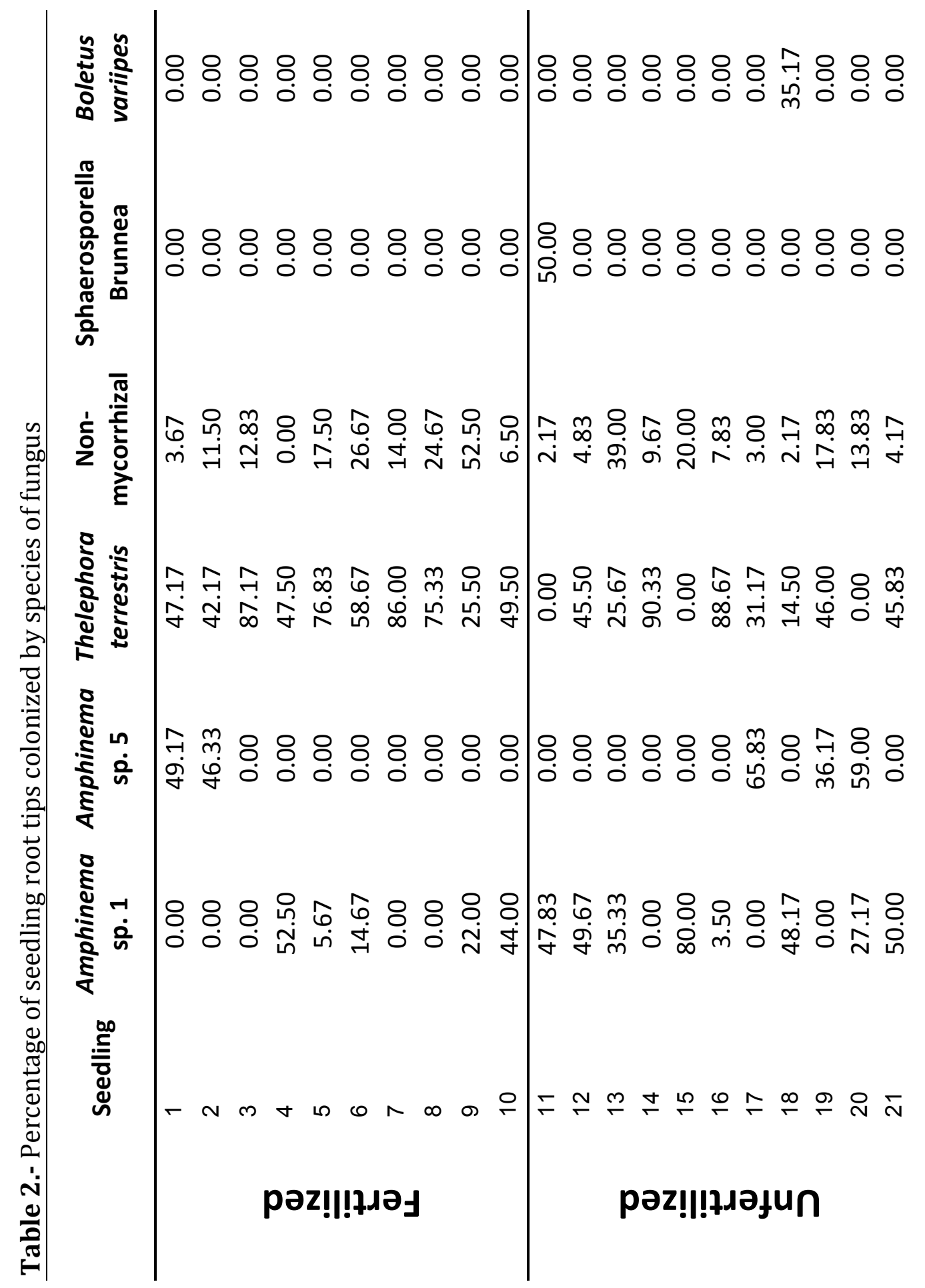


Table 3.- Specifications for thermocycler program DS35

\begin{tabular}{c|ccc}
\hline & Temp ( C ) & Time & Cycles \\
\hline Initial & 94 & $1.25 \mathrm{~min}$ & 1 \\
Denaturation & & $35 \mathrm{sec}$ & \\
Denaturation & 95 & $55 \mathrm{sec}$ & 35 \\
Annealing & 44 & $42 \mathrm{sec}$ & \\
Extension & 72 & $10 \mathrm{~min}$ & 1 \\
Final Extension & 72 & Indefinitely & \\
Hold & 10 &
\end{tabular}




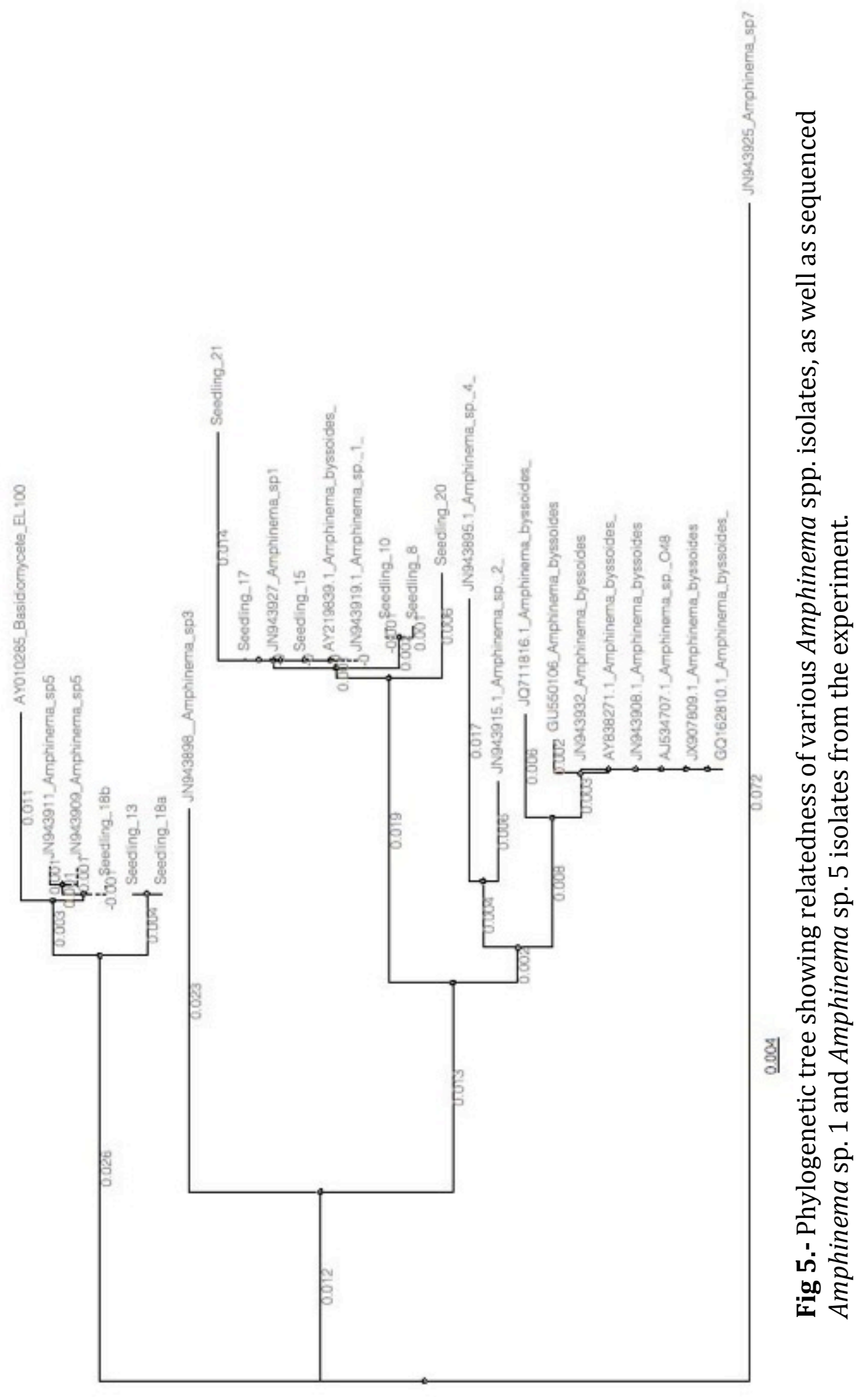




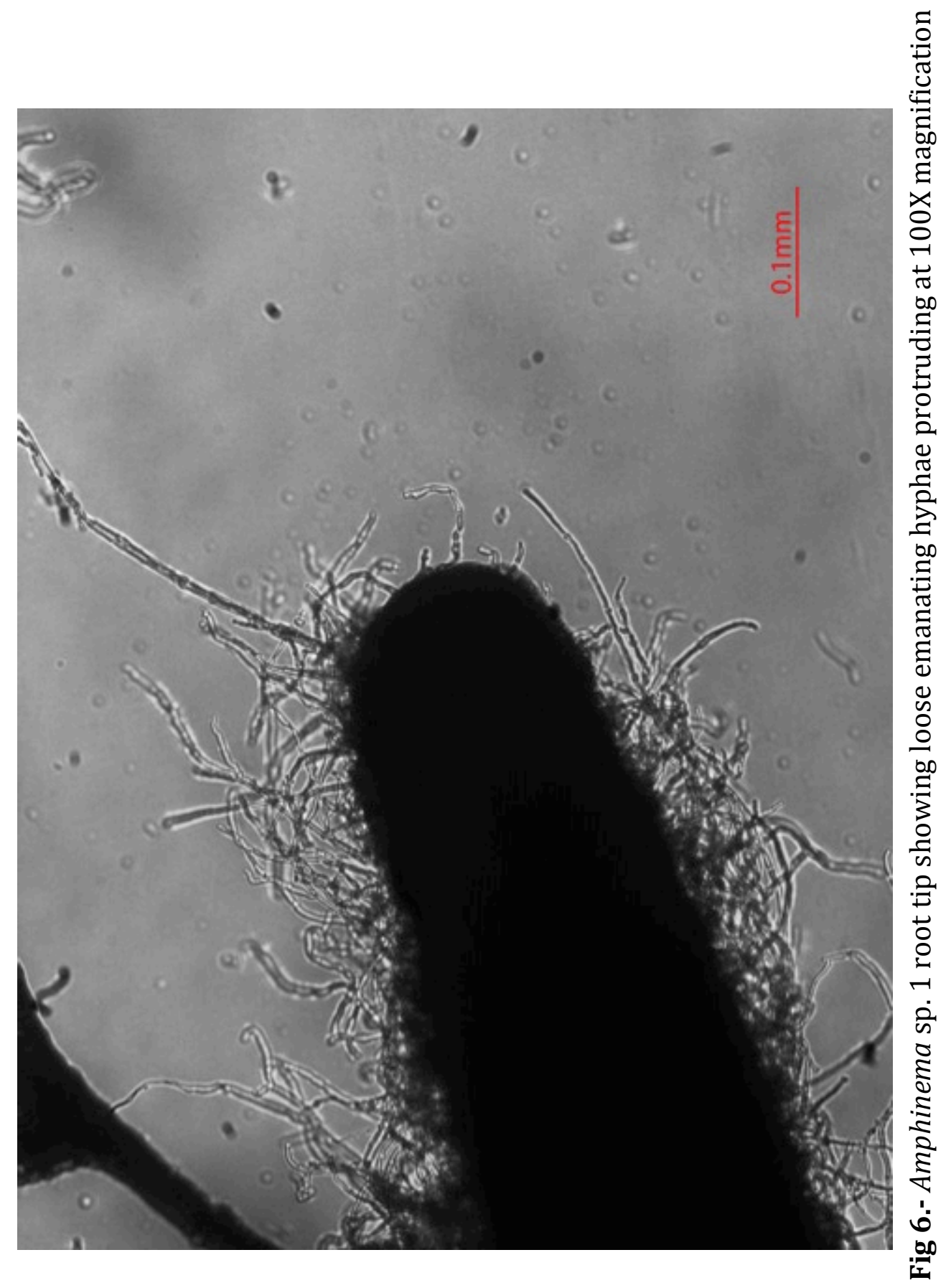




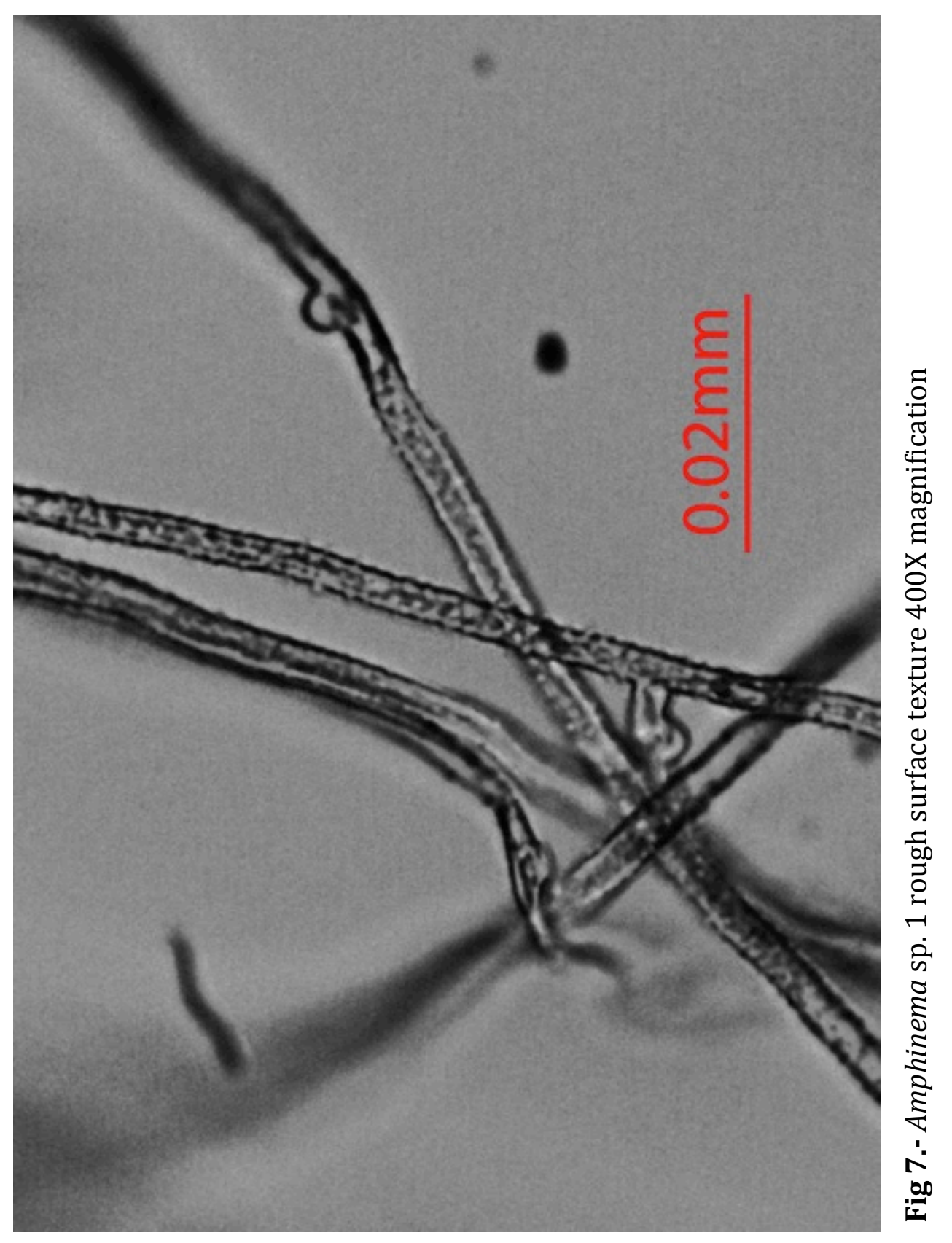




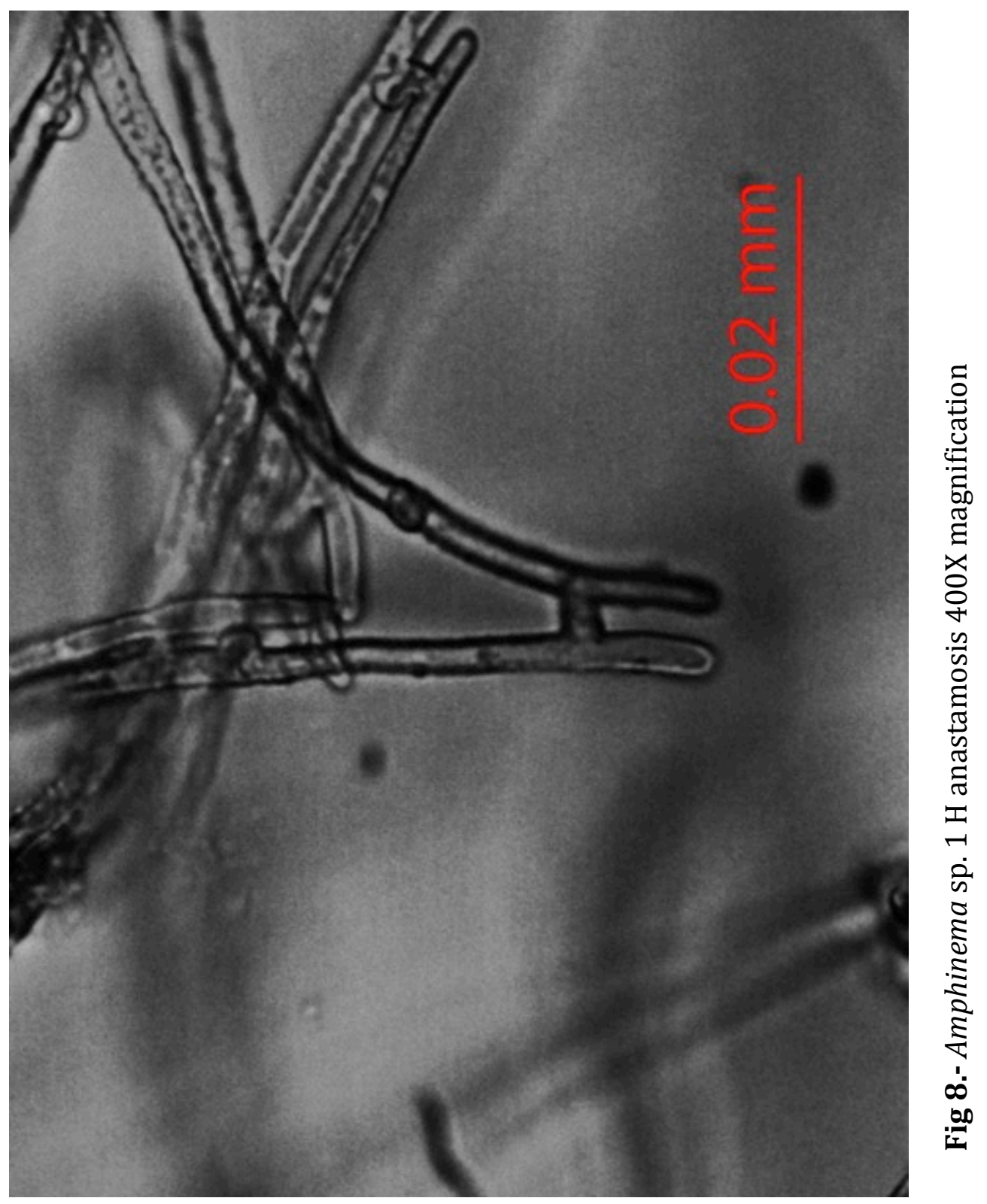




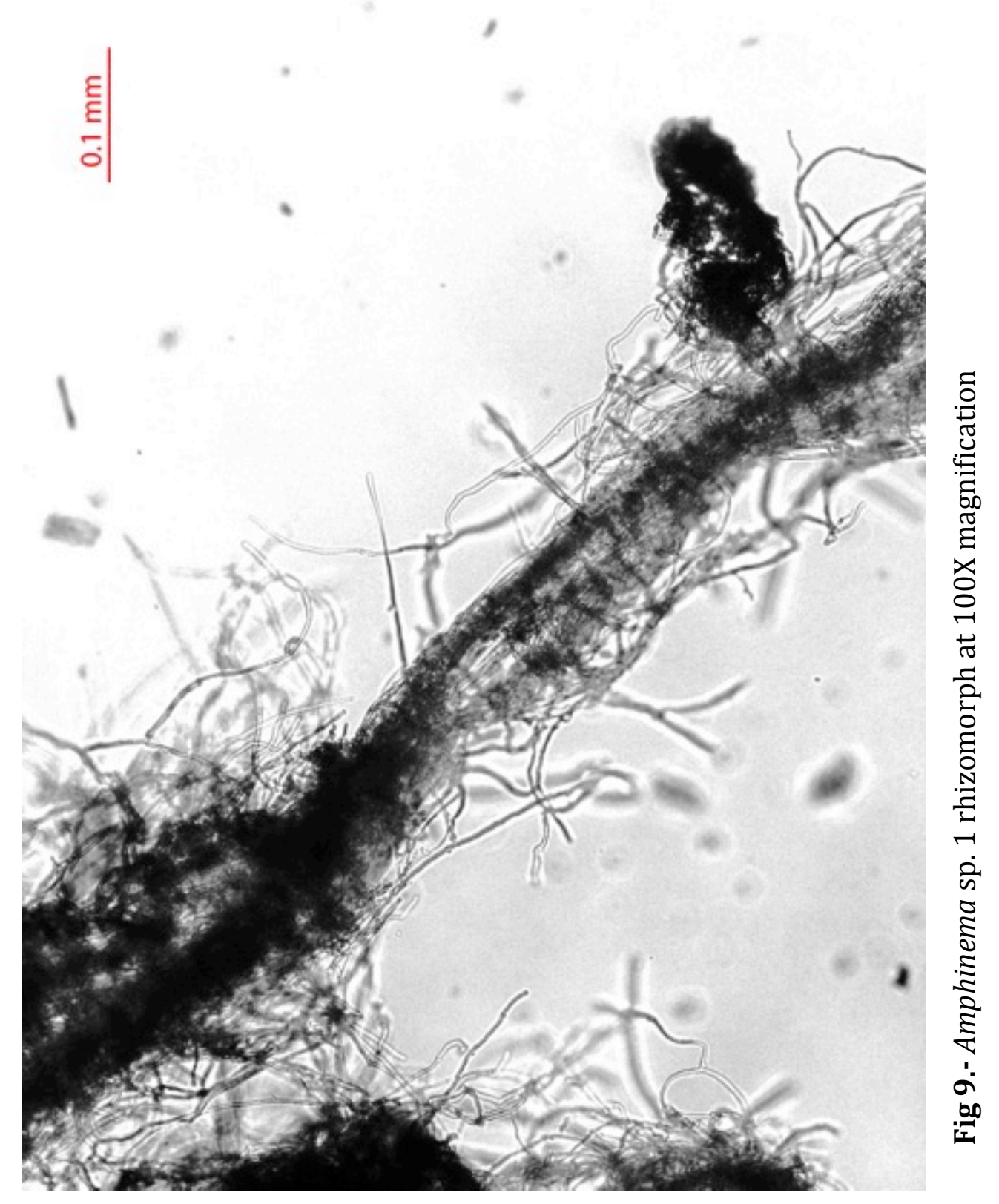




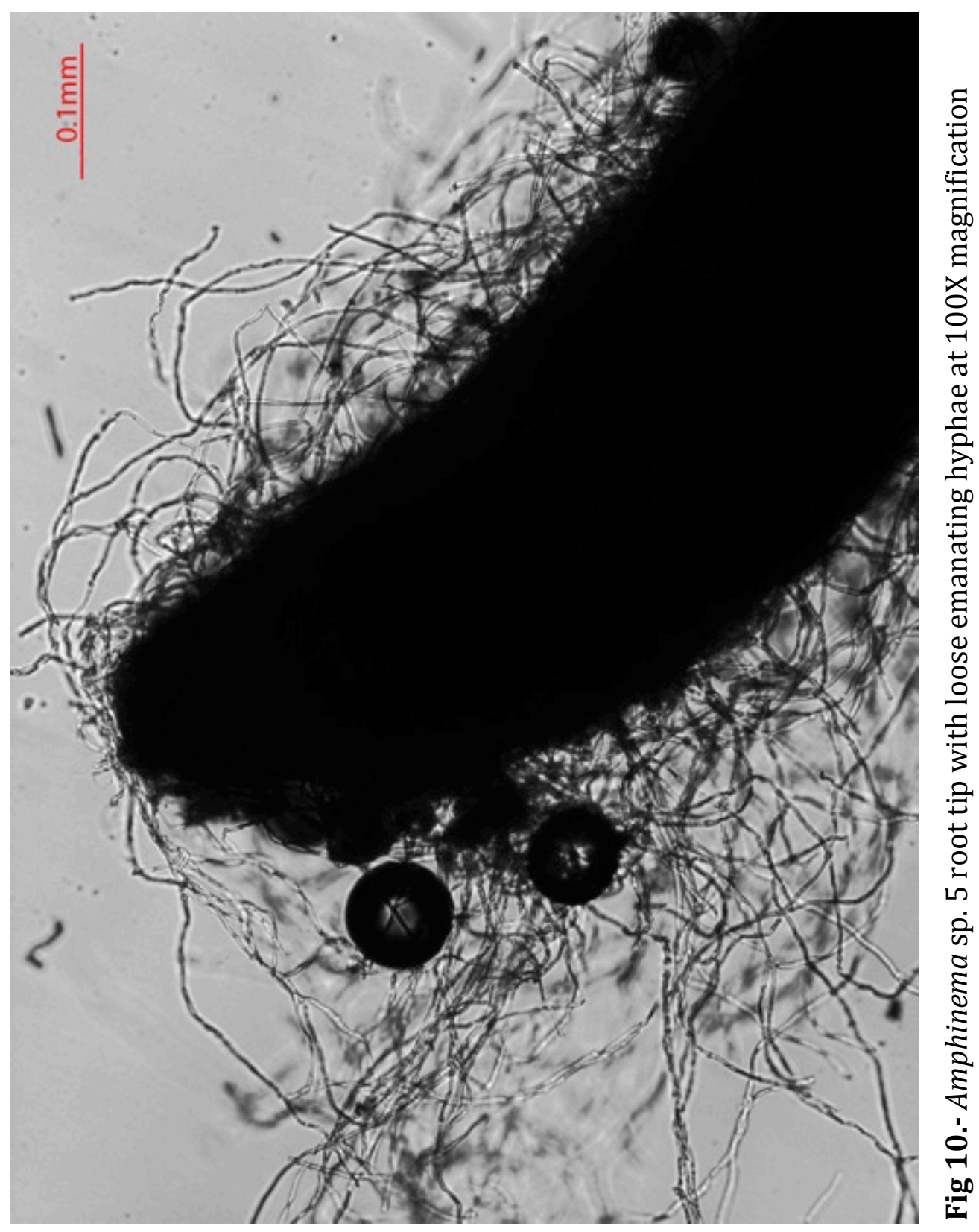




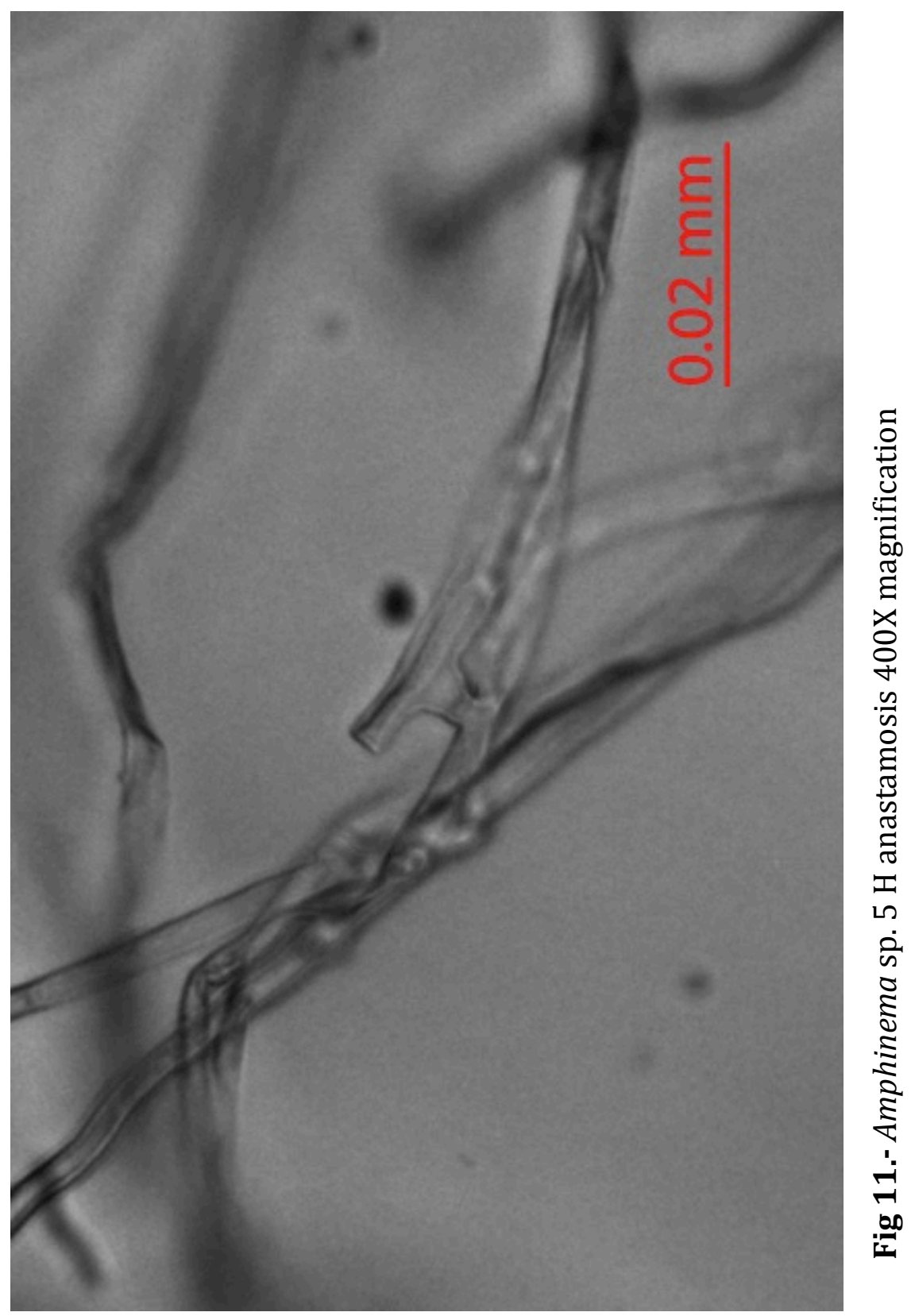




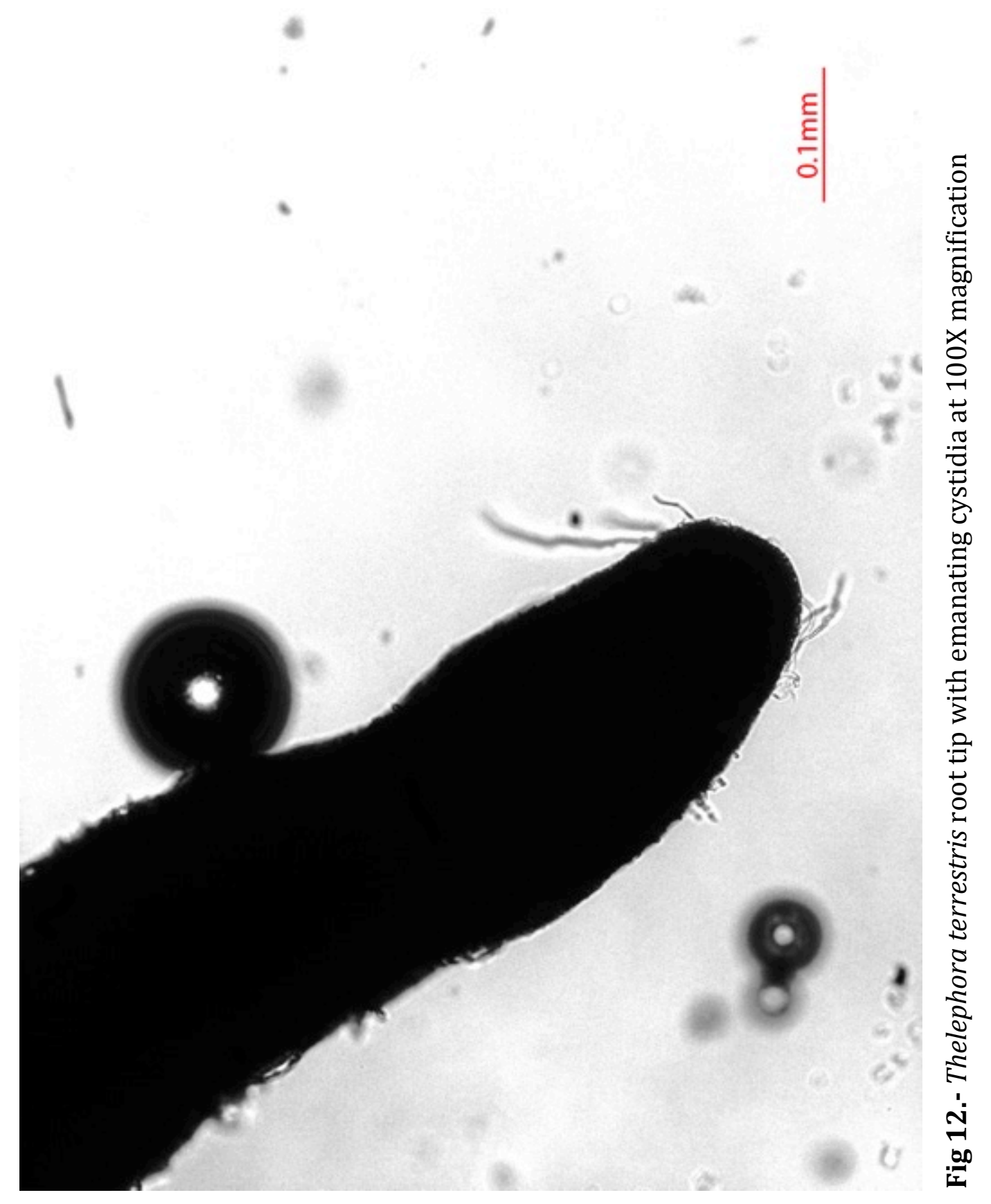




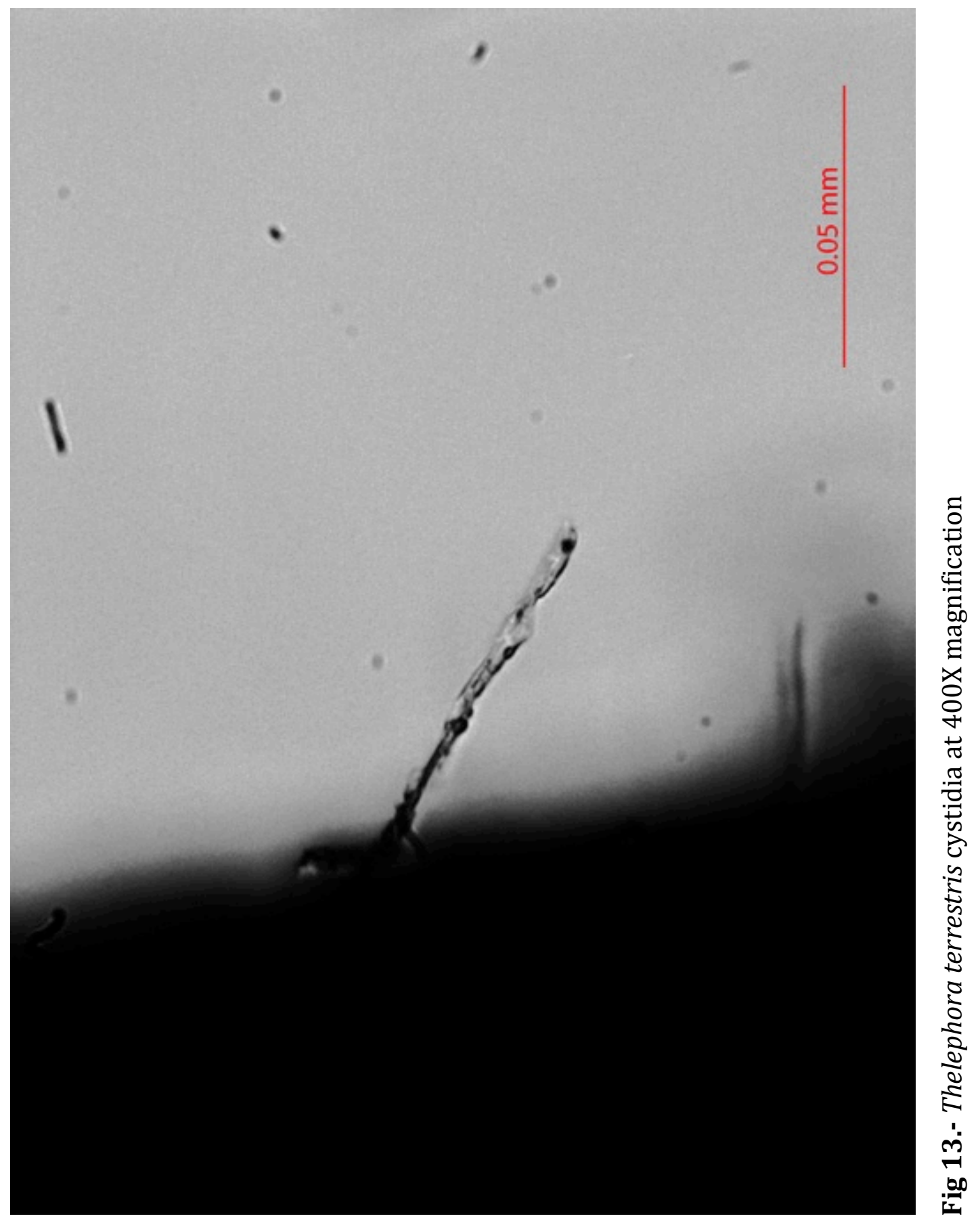




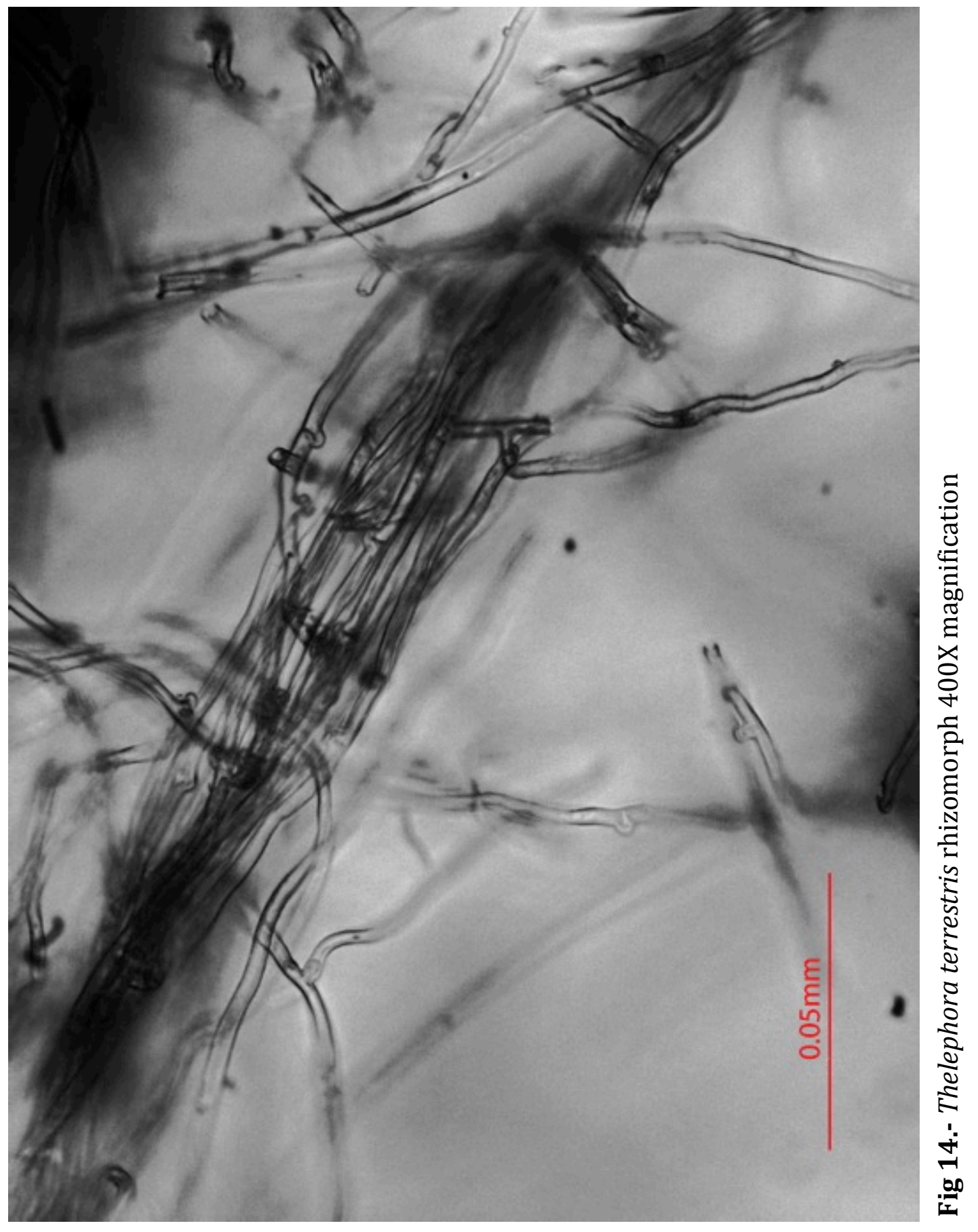



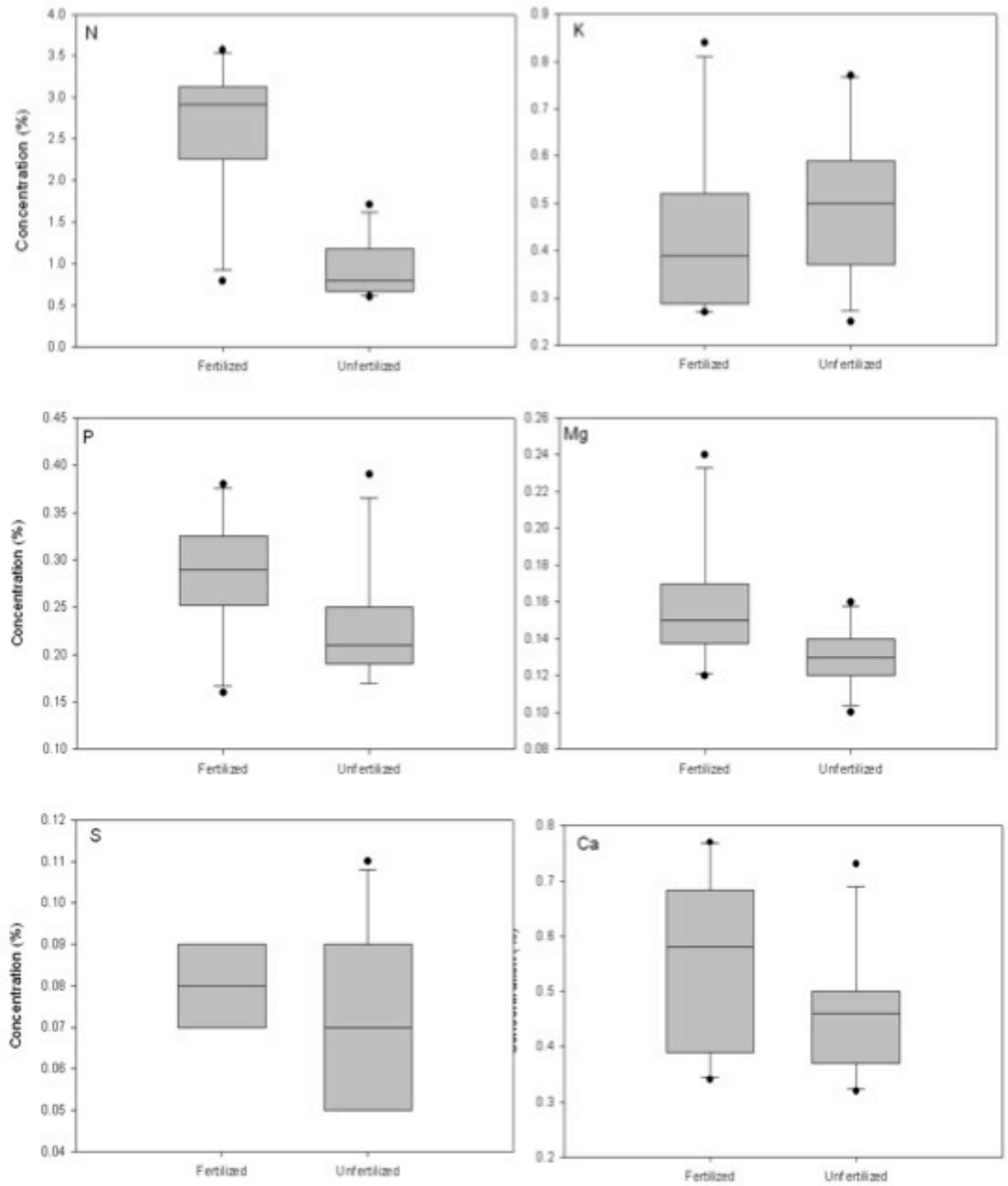

Fig 15.- Comparison of nutrient content for two treatment types (N, P, K, Ca, $\mathrm{Mg}, \mathrm{S})$ 

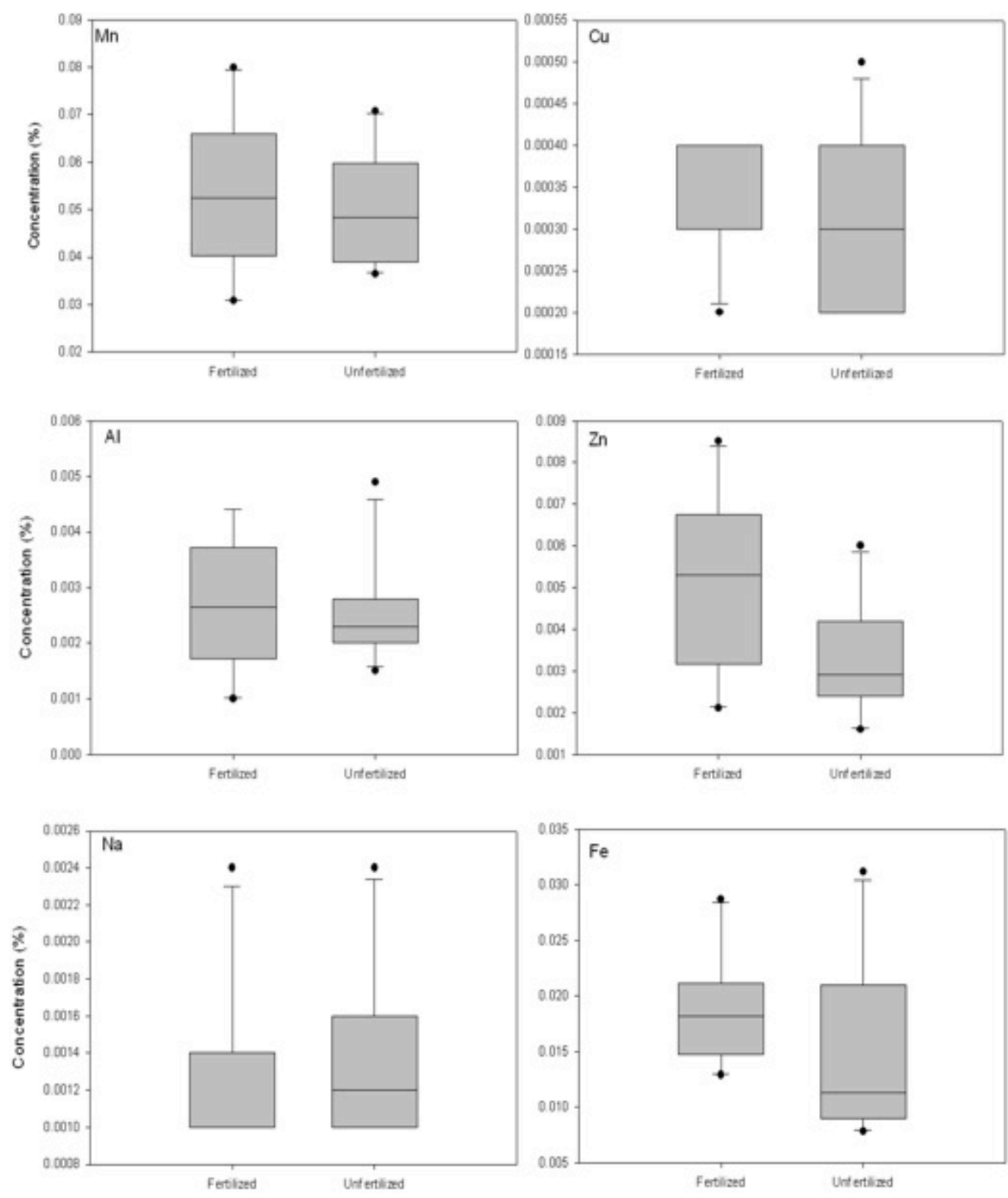

Fig 16.- Comparison of nutrient content for two treatment types $\mathrm{Mn}, \mathrm{Cu}$, $\mathrm{Al}, \mathrm{Zn}, \mathrm{Na}, \mathrm{Fe}$ ) 


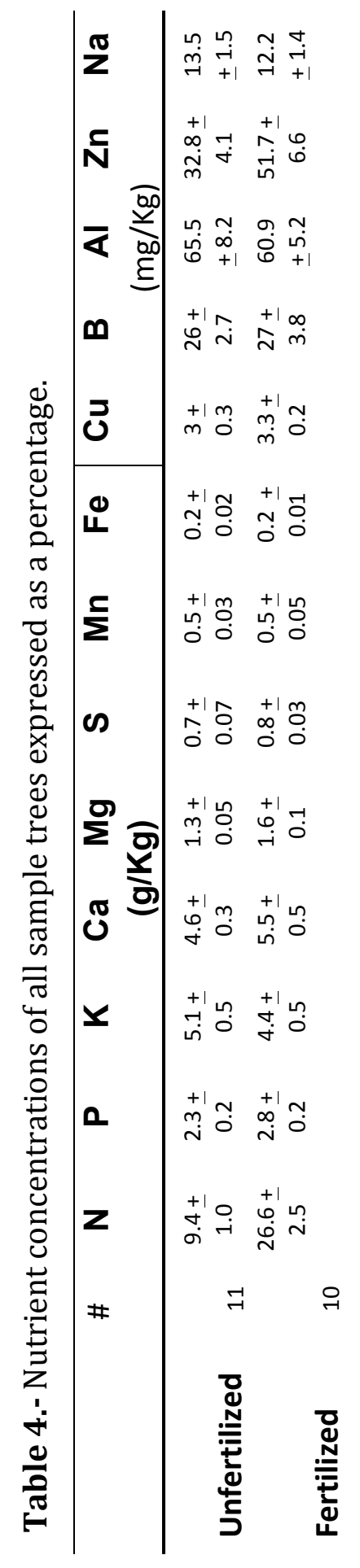




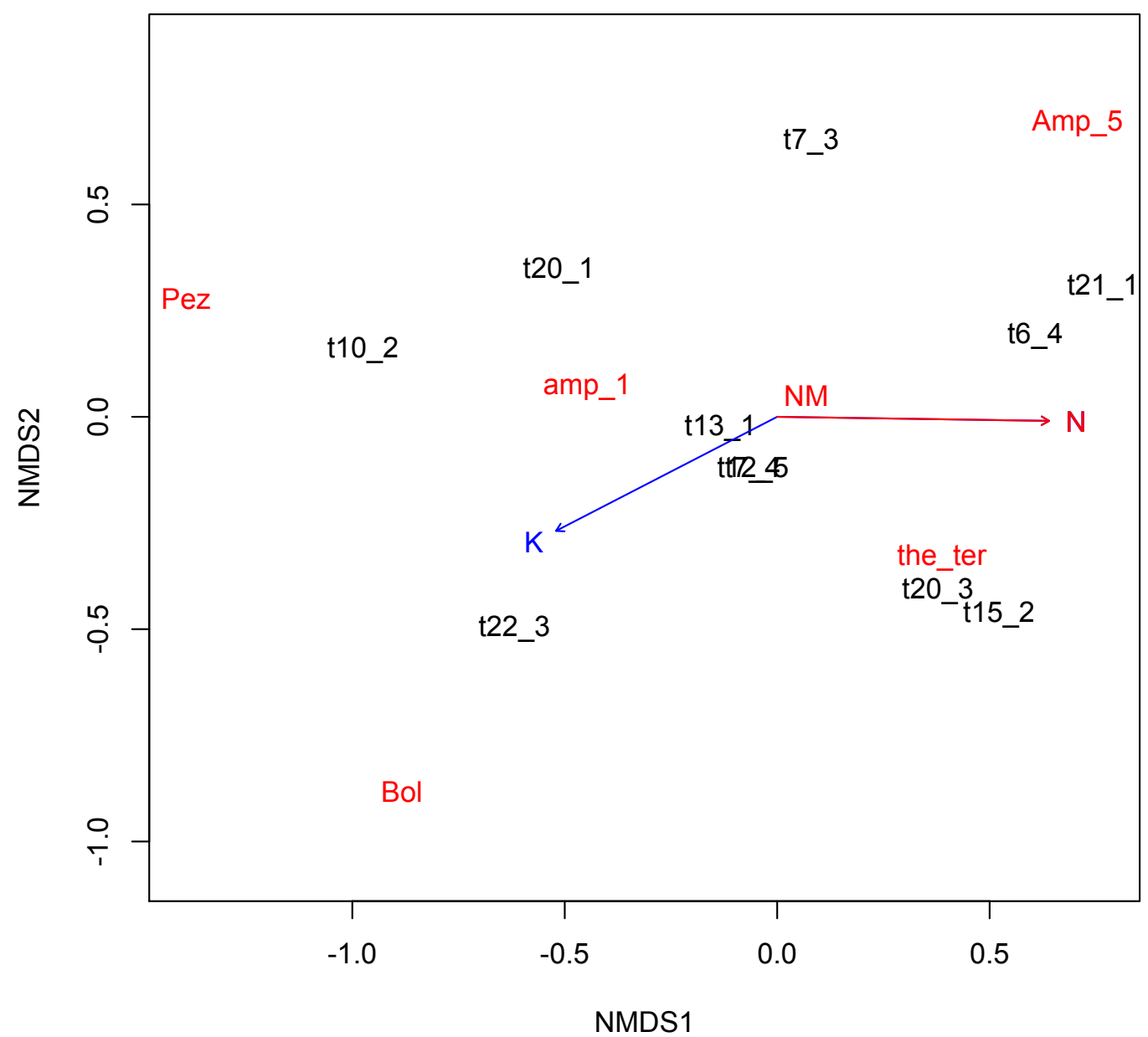

Fig 17.- Non-metric multidimensional scaling (NMDS) ordination analysis of EcMF communities on seedlings with EnvFit correlations of foliar nutrient concentrations to the ordination axes for unfertilized seedlings. Bol represents Boletus variipes, Pez represents Sphaerosporella brunnea, amp_1 represents Amphinema sp. 1, Amp_5 represents Amphinema sp. 5, the_ter represents Thelephora terrestris, and t\#_\# represent seedlings. Red arrows indicate signicant trends $(\mathrm{p}<0.05)$, while blue arrows represent marginally significant trends $(\mathrm{p}<0.1)$. 


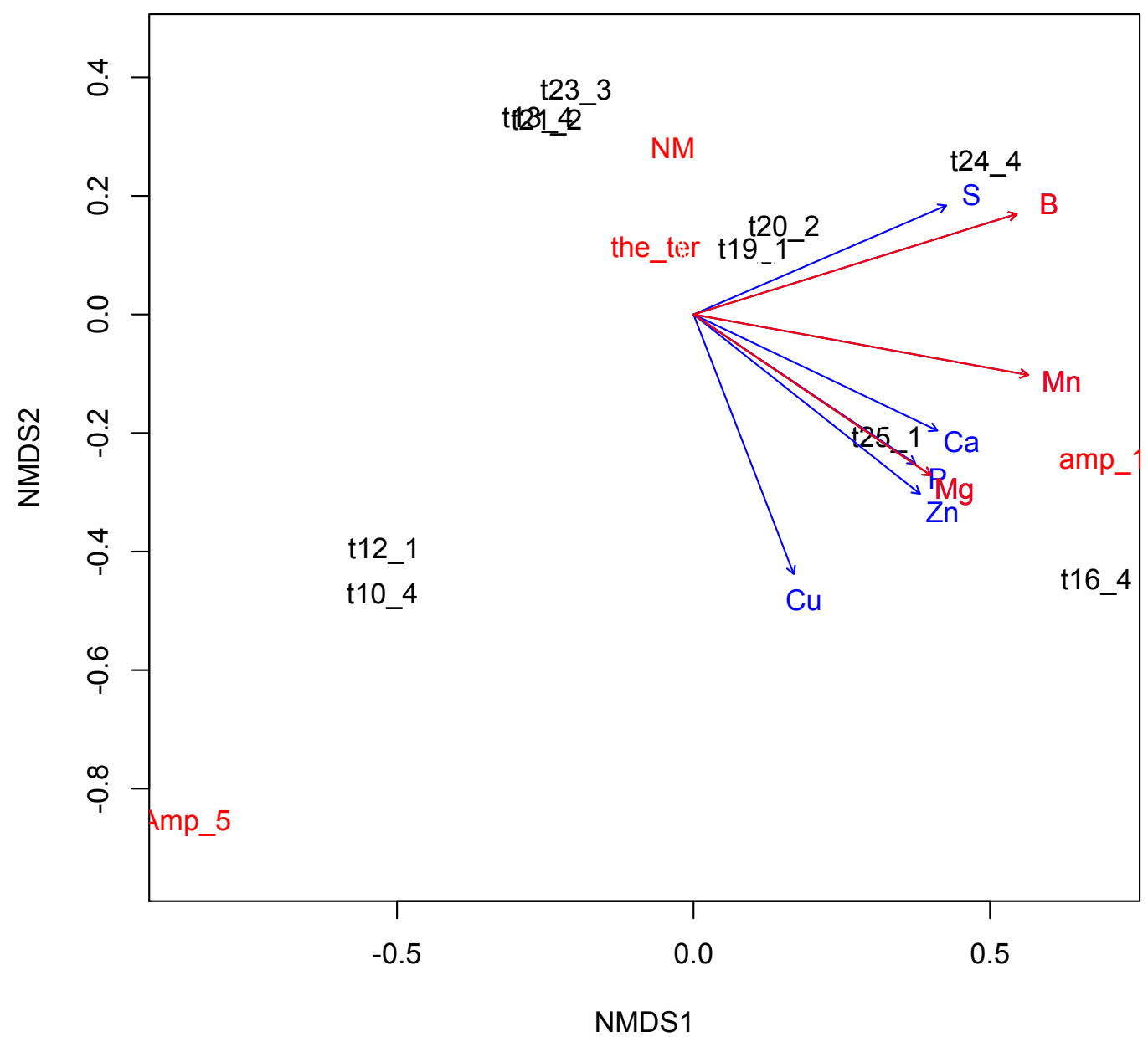

Fig 18.- Non-metric multidimensional scaling (NMDS) ordination analysis of EcMF communities on seedlings with EnvFit correlations of foliar nutrient concentrations to the ordination axes for fertilized seedlings. Bol represents Boletus variipes, Pez represents Sphaerosporella brunnea, amp_1 represents Amphinema sp. 1, Amp_5 represents Amphinema sp. 5, the_ter represents Thelephora terrestris, and $\mathrm{t} \#$ _\# represent seedlings Red arrows indicate signicant trends $(\mathrm{p}<0.05)$, while blue arrows represent marginally significant trends $(\mathrm{p}<0.1)$. 


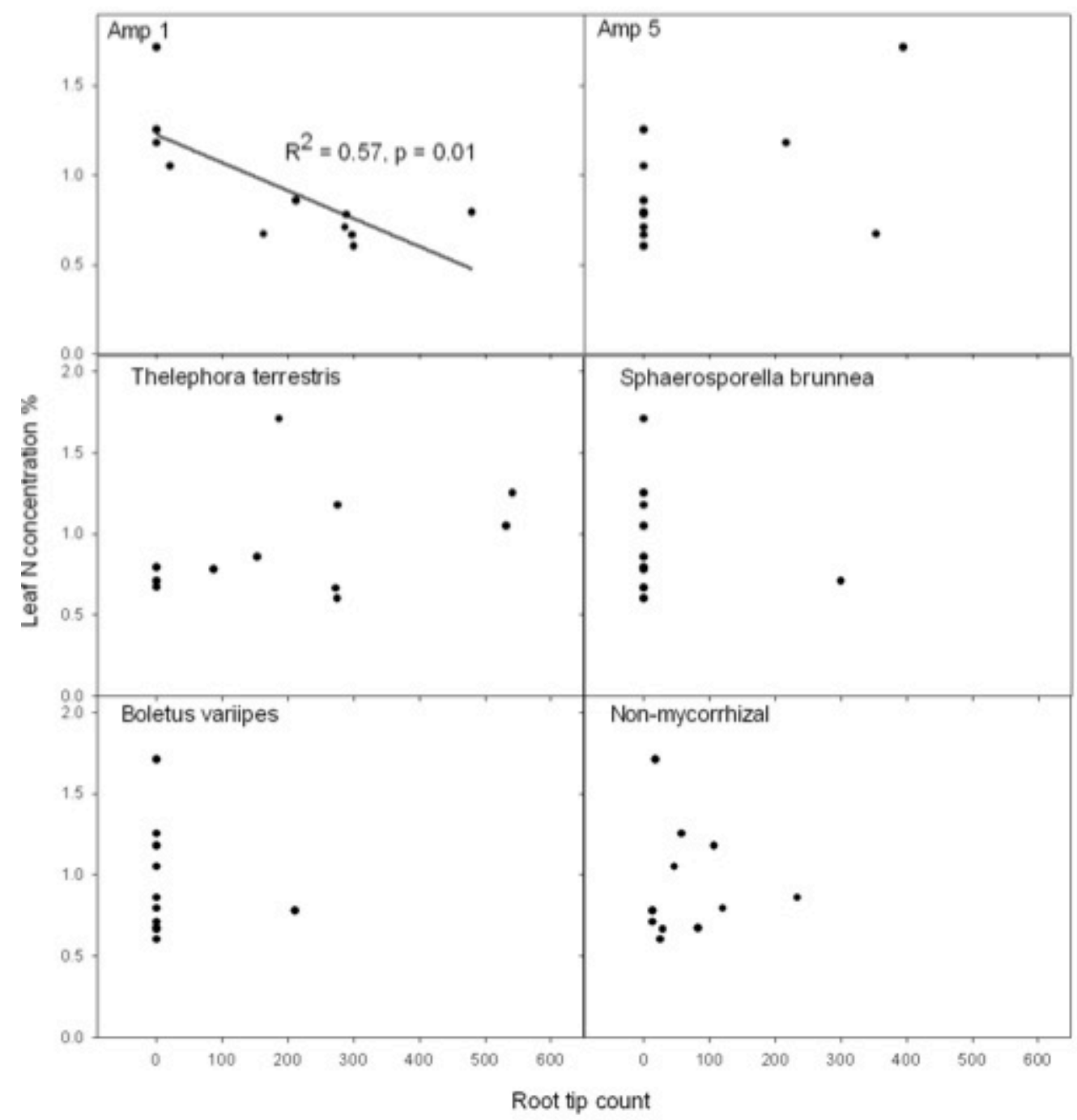

Fig 19.- Relationships between fungal species and foliar nitrogen concentration of unfertilized seedlings. 


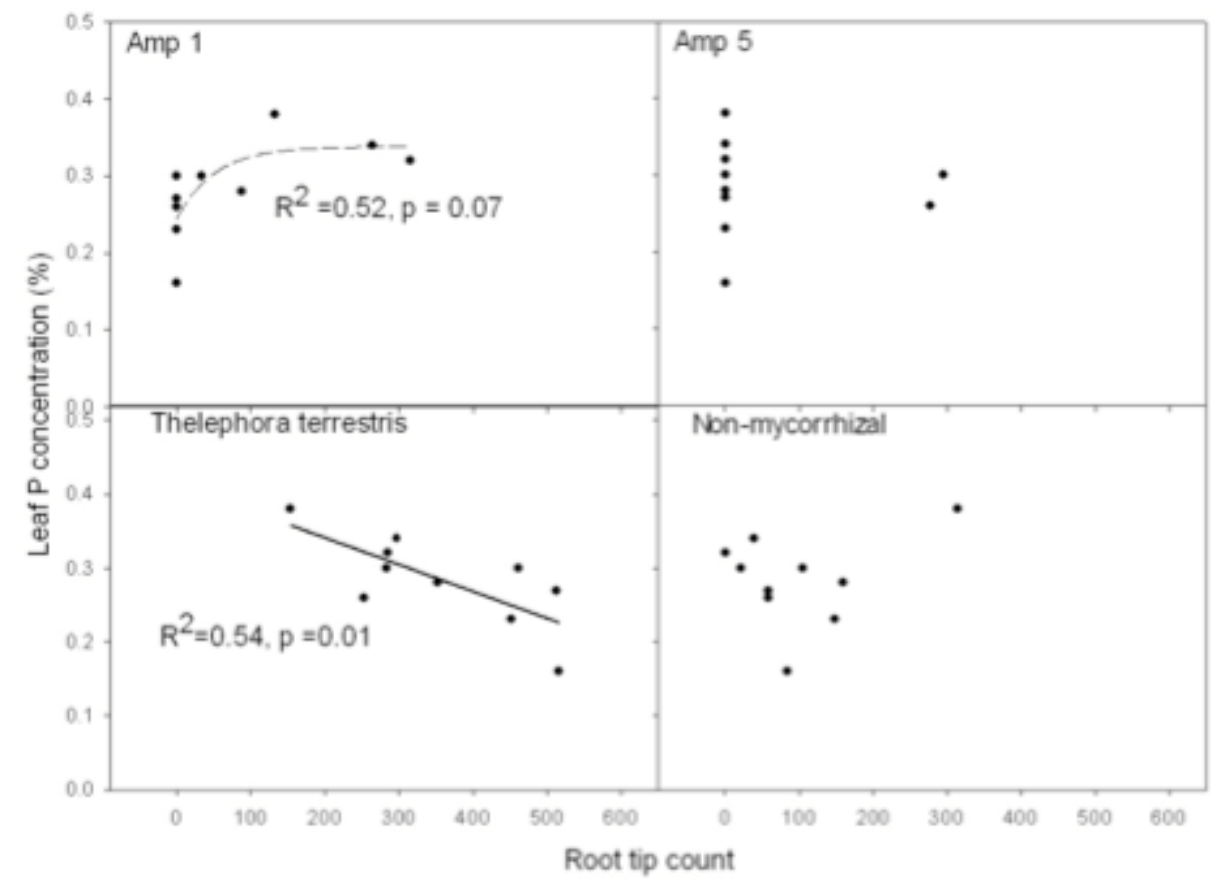

Fig 20.- Relationships between fungal species and foliar phosphorus concentration of fertilized seedlings.

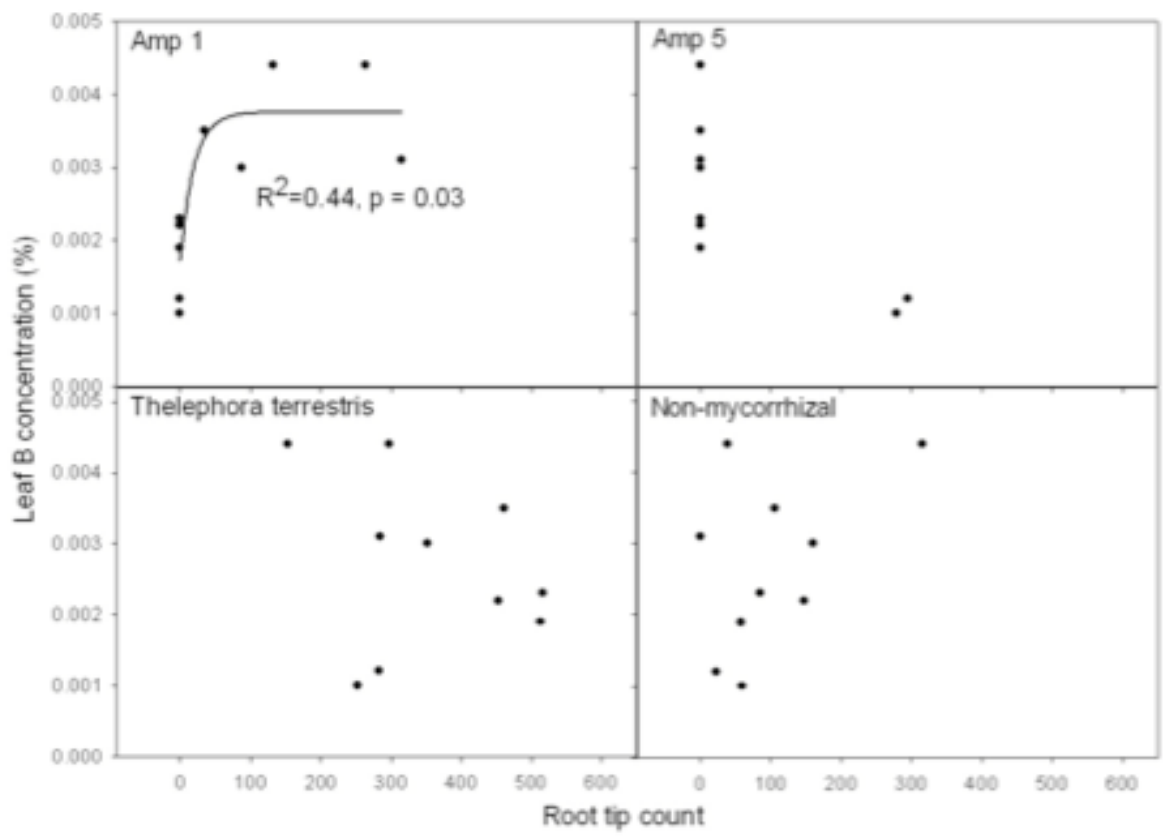

Fig 21.- Relationships between fungal species and foliar boron concentration of fertilized seedlings. 


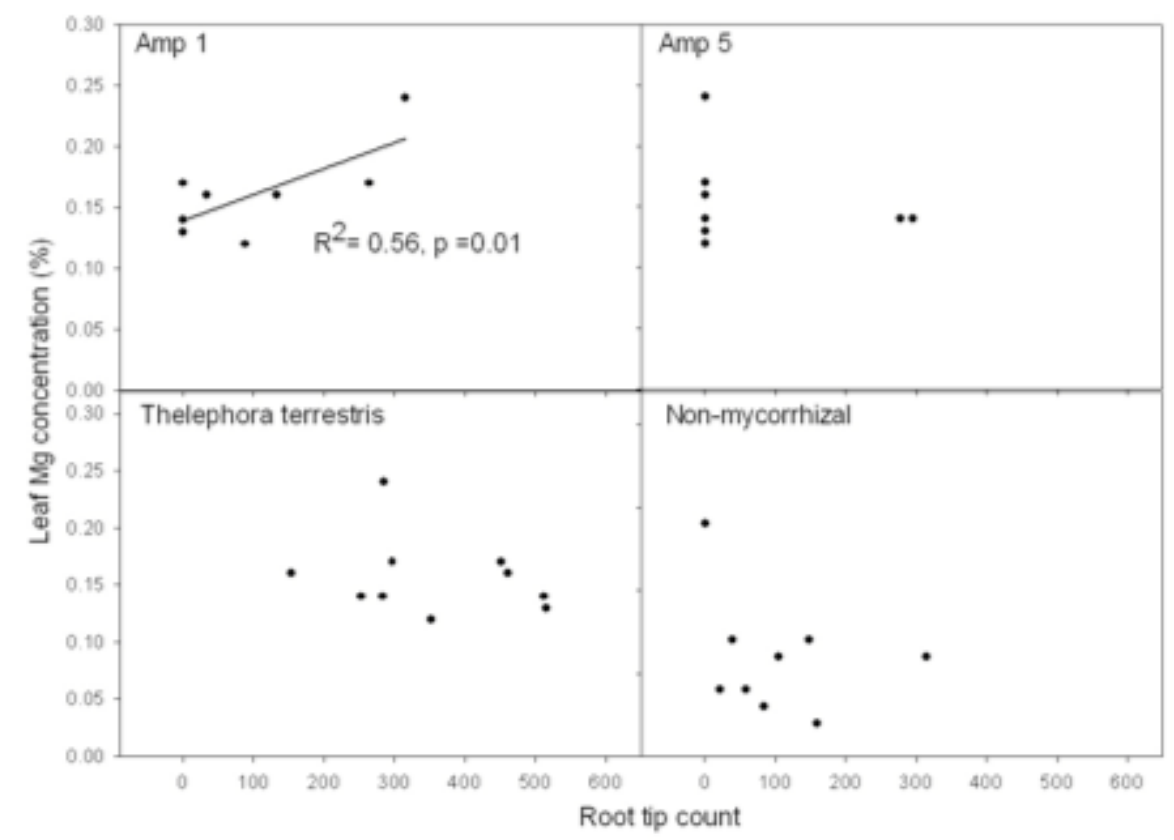

Fig 22.- Relationships between fungal species and foliar magnesium concentration of fertilized seedlings.

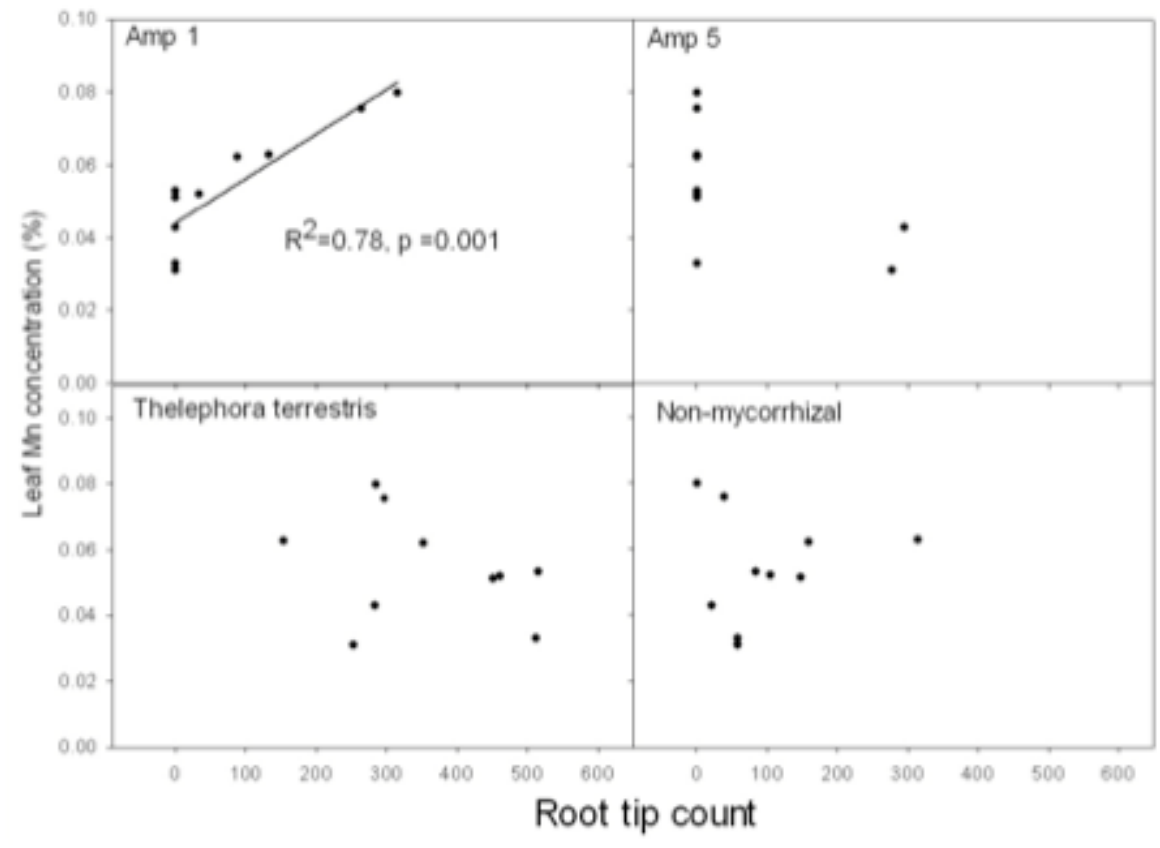

Fig 23.- Relationships between fungal species and foliar manganese concentration of fertilized seedlings. 


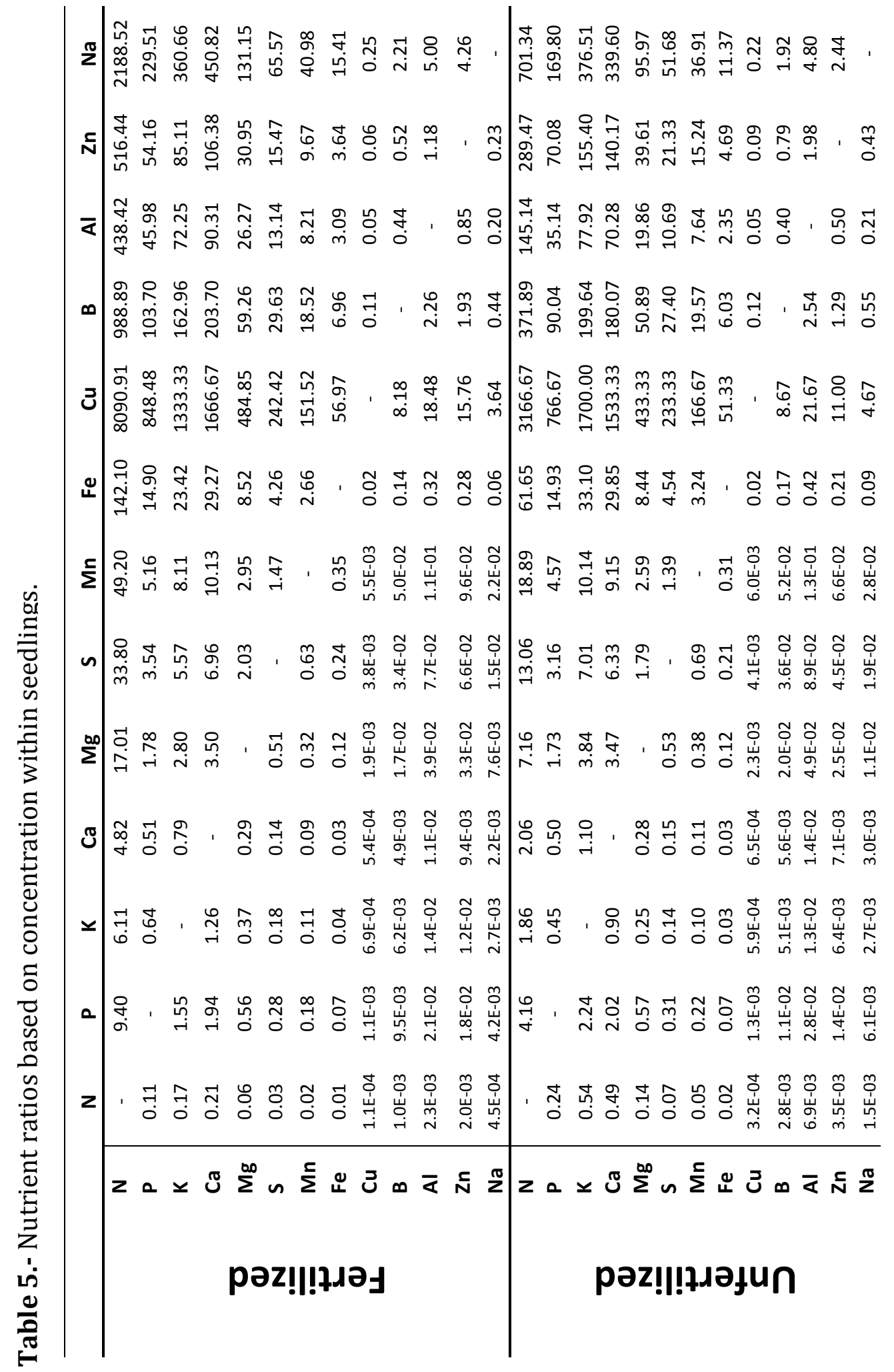




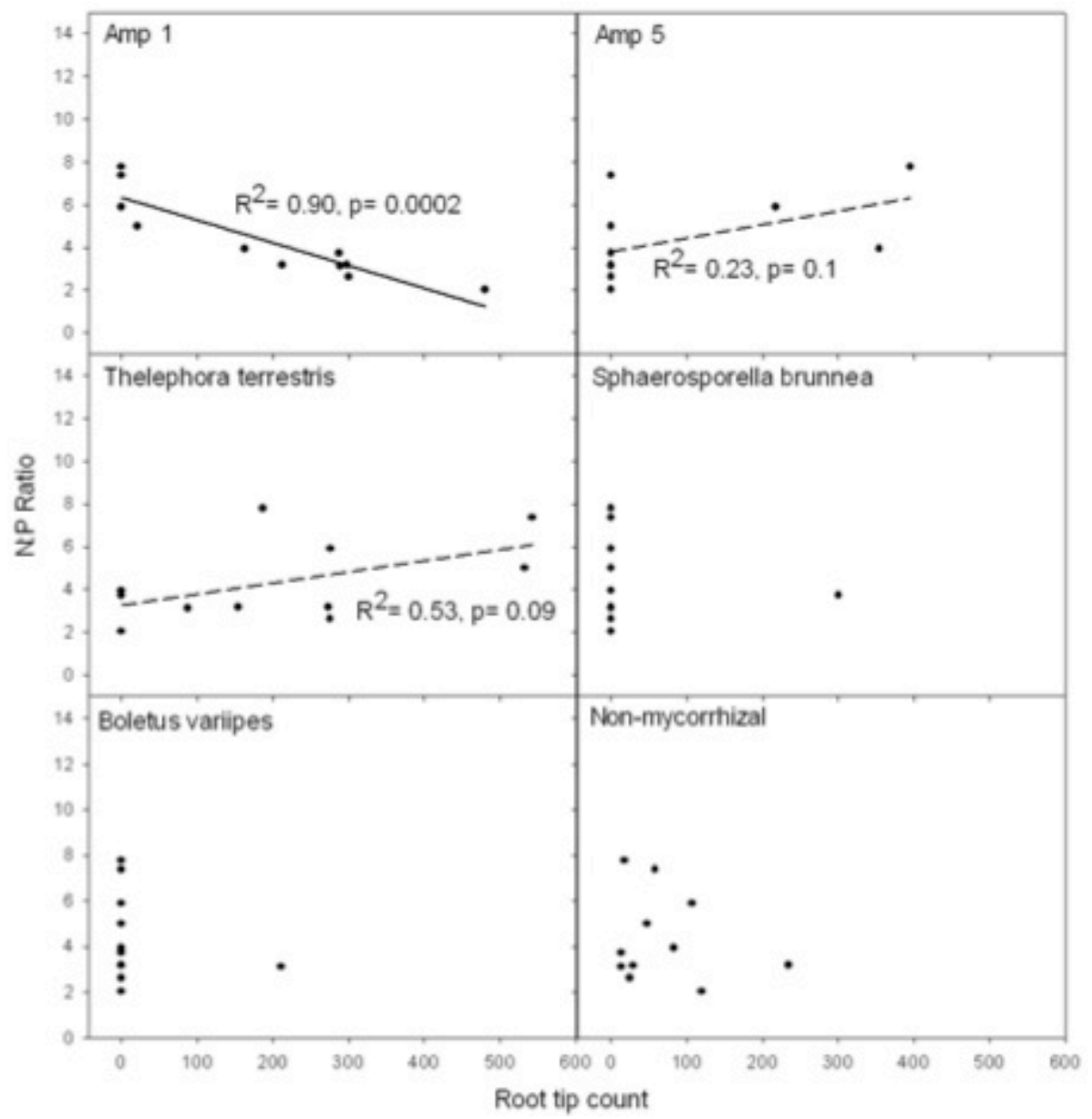

Figure 24.- Ratio of N:P in unfertilized seedlings. 


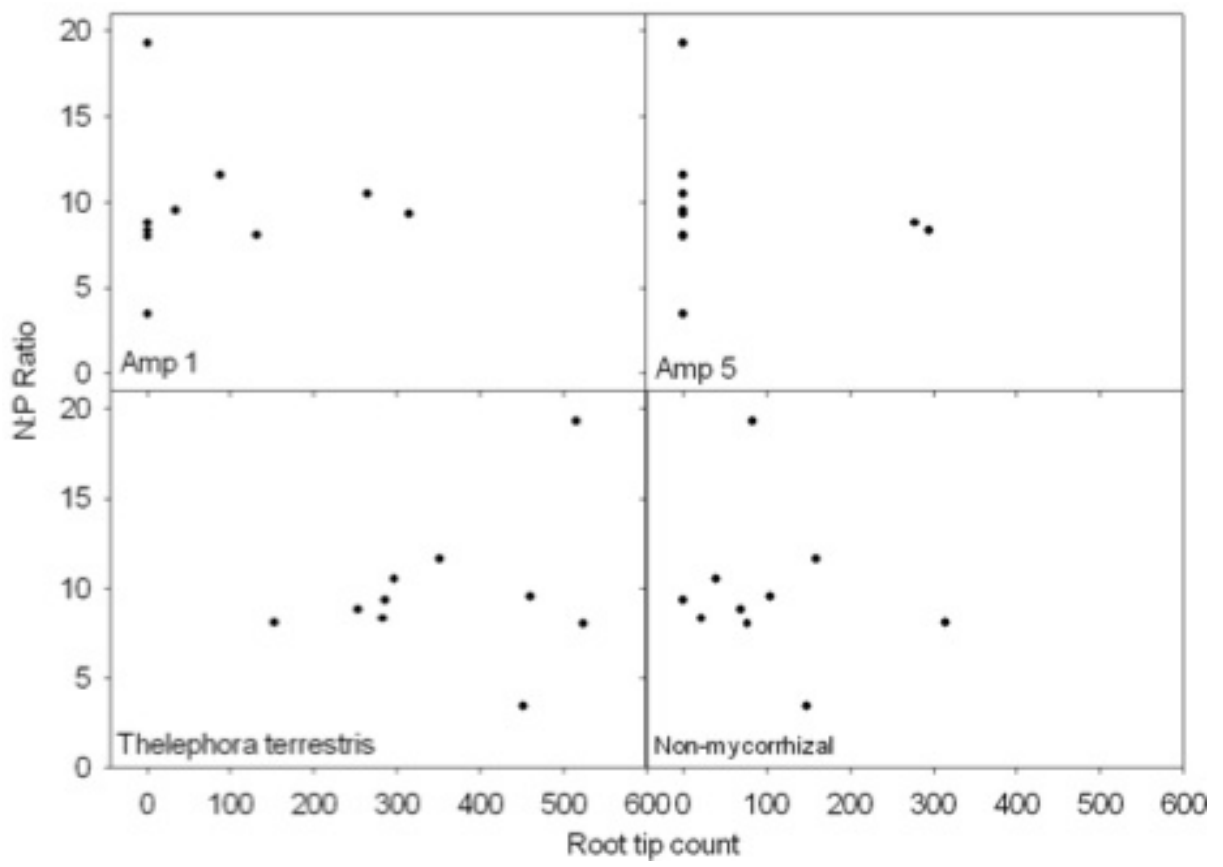

Figure 25.- Ratio of N:P in fertilized seedlings 


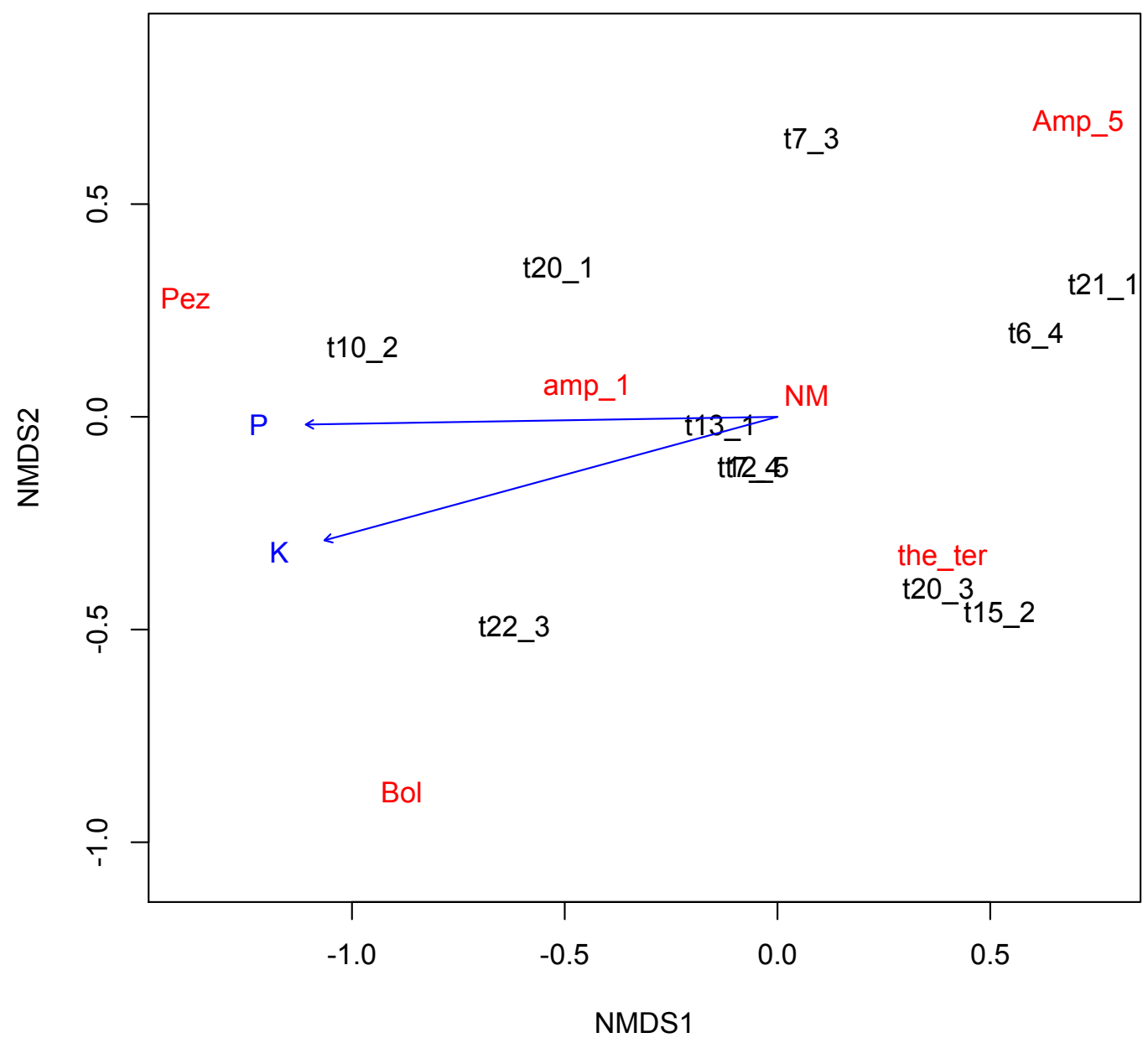

Fig 26.- Non-metric multidimensional scaling (NMDS) ordination analysis of EcMF communities on seedlings with EnvFit correlations of foliar nutrient content to the ordination axes for unfertilized seedlings. Bol represents Boletus variipes, Pez represents Sphaerosporella brunnea, amp_1 represents Amphinema sp. 1, Amp_5 represents Amphinema sp. 5, the_ter represents Thelephora terrestris, and t\#_\# represent seedlings. Red arrows indicate signicant trends $(\mathrm{p}<0.05)$, while blue arrows represent marginally significant trends $(\mathrm{p}<0.1)$. 


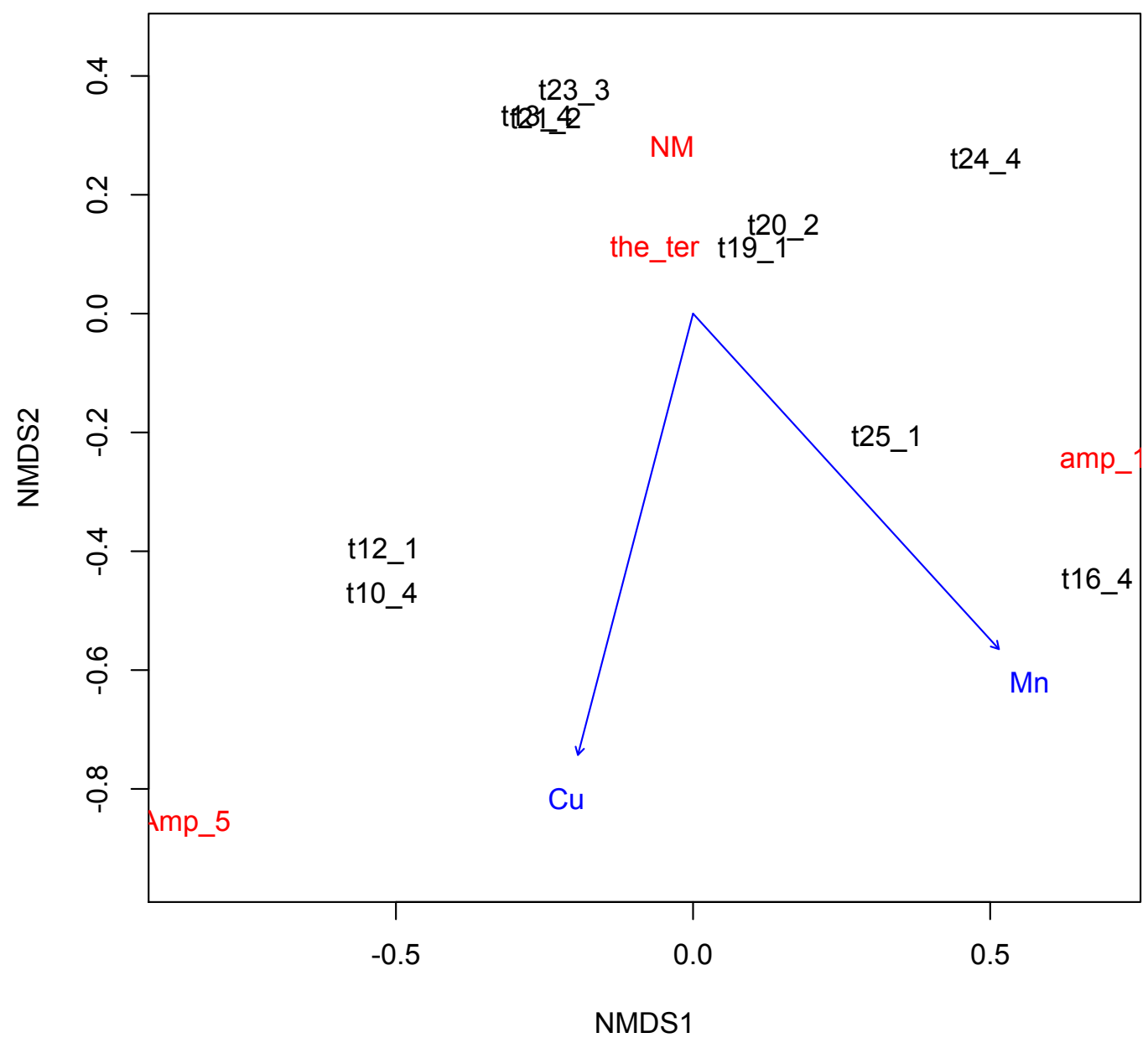

Fig 27.- Non-metric multidimensional scaling (NMDS) ordination analysis of EcMF communities on seedlings with EnvFit correlations of foliar nutrient content to the ordination axes for fertilized seedlings. Bol represents Boletus variipes, Pez represents Sphaerosporella brunnea, amp_1 represents Amphinema sp. 1, Amp_5 represents Amphinema sp. 5, the_ter represents Thelephora terrestris, and t\#_\# represent seedlings. Red arrows indicate signicant trends $(\mathrm{p}<0.05)$, while blue arrows represent marginally significant trends $(\mathrm{p}<0.1)$. 


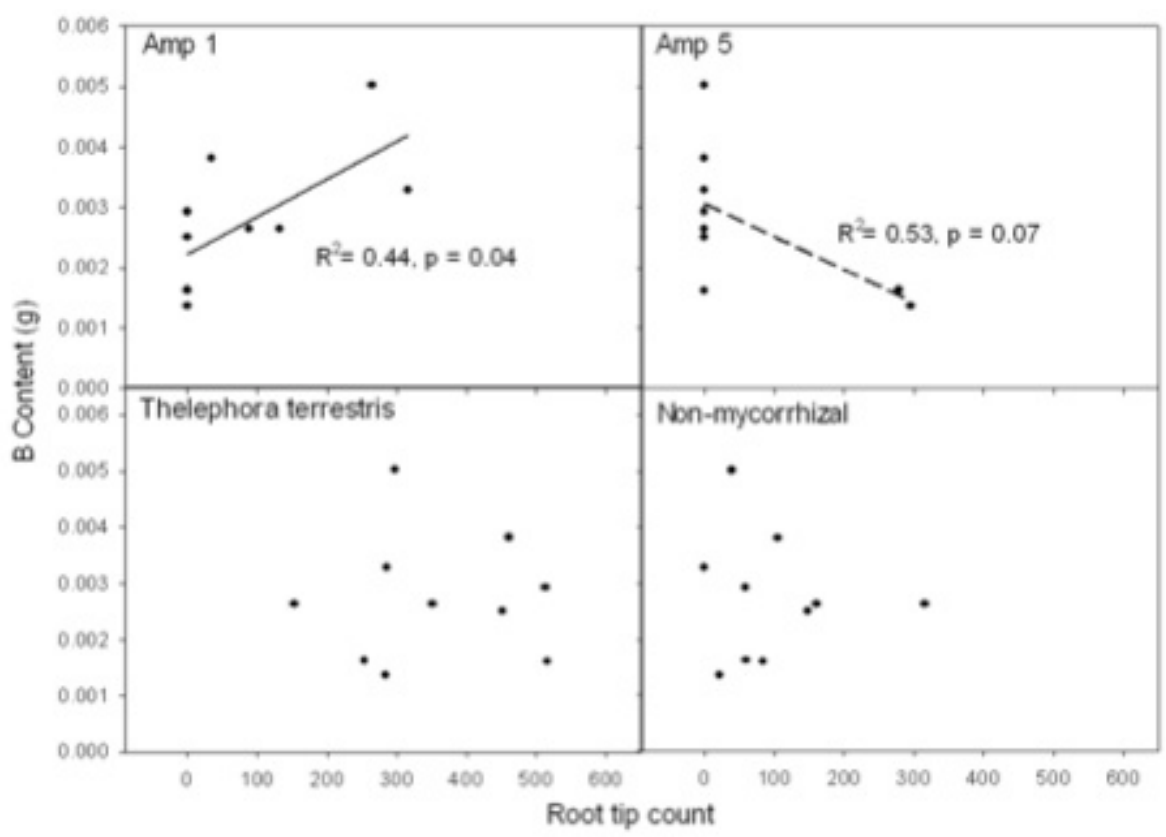

Fig 28.- Relationships between fungal species and foliar boron content of fertilized seedlings. A significant positive trend was observed in Amphinema sp. 1.

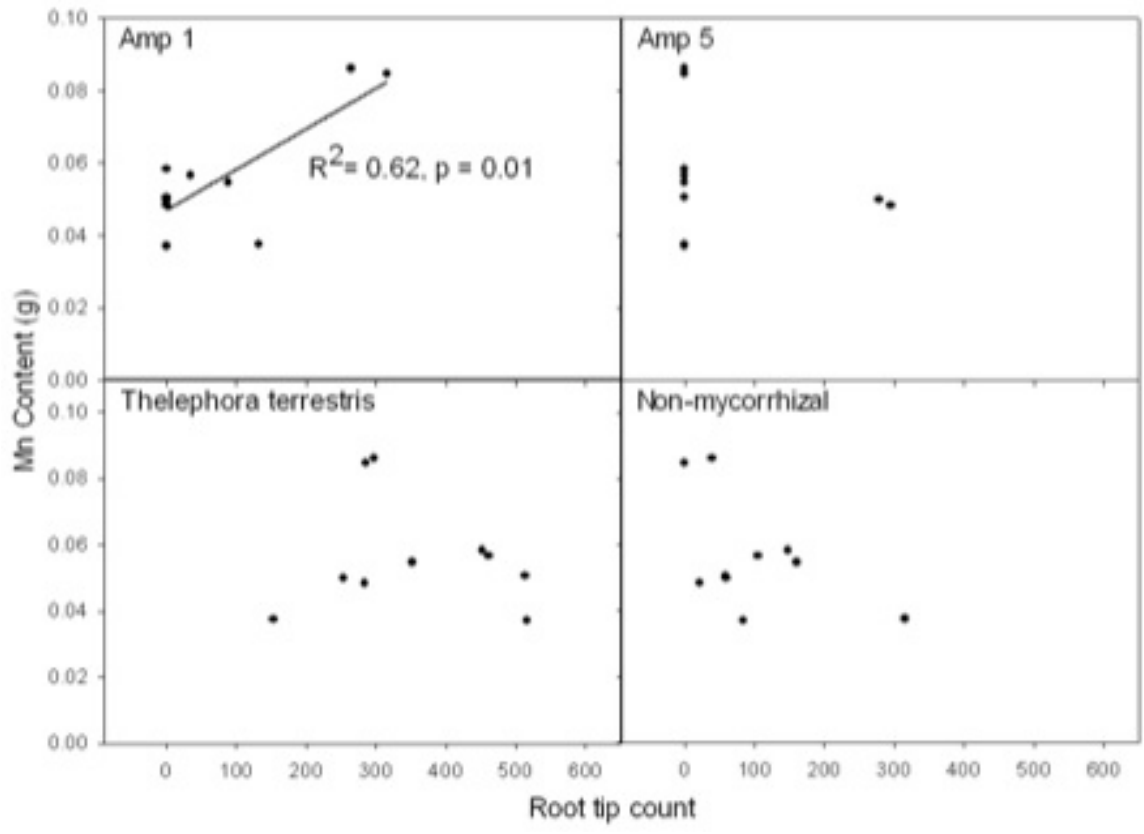

Fig 29.- Relationships between fungal species and foliar manganese content of fertilized seedlings. A significant positive trend was observed in Amphinema sp. 1. 


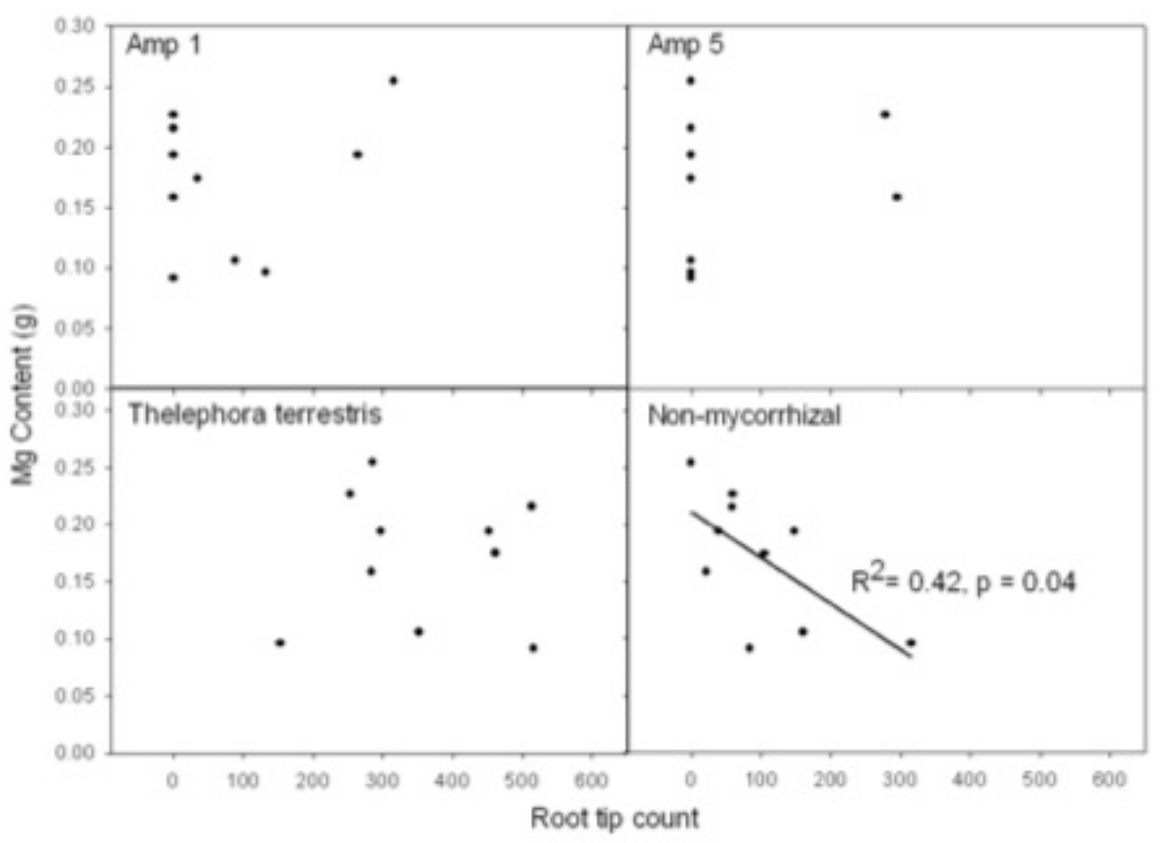

Fig 30.- Relationships between fungal species and foliar magnesium content of fertilized seedlings. A significant negative trend was observed in nonmycorrhizal root tips. 


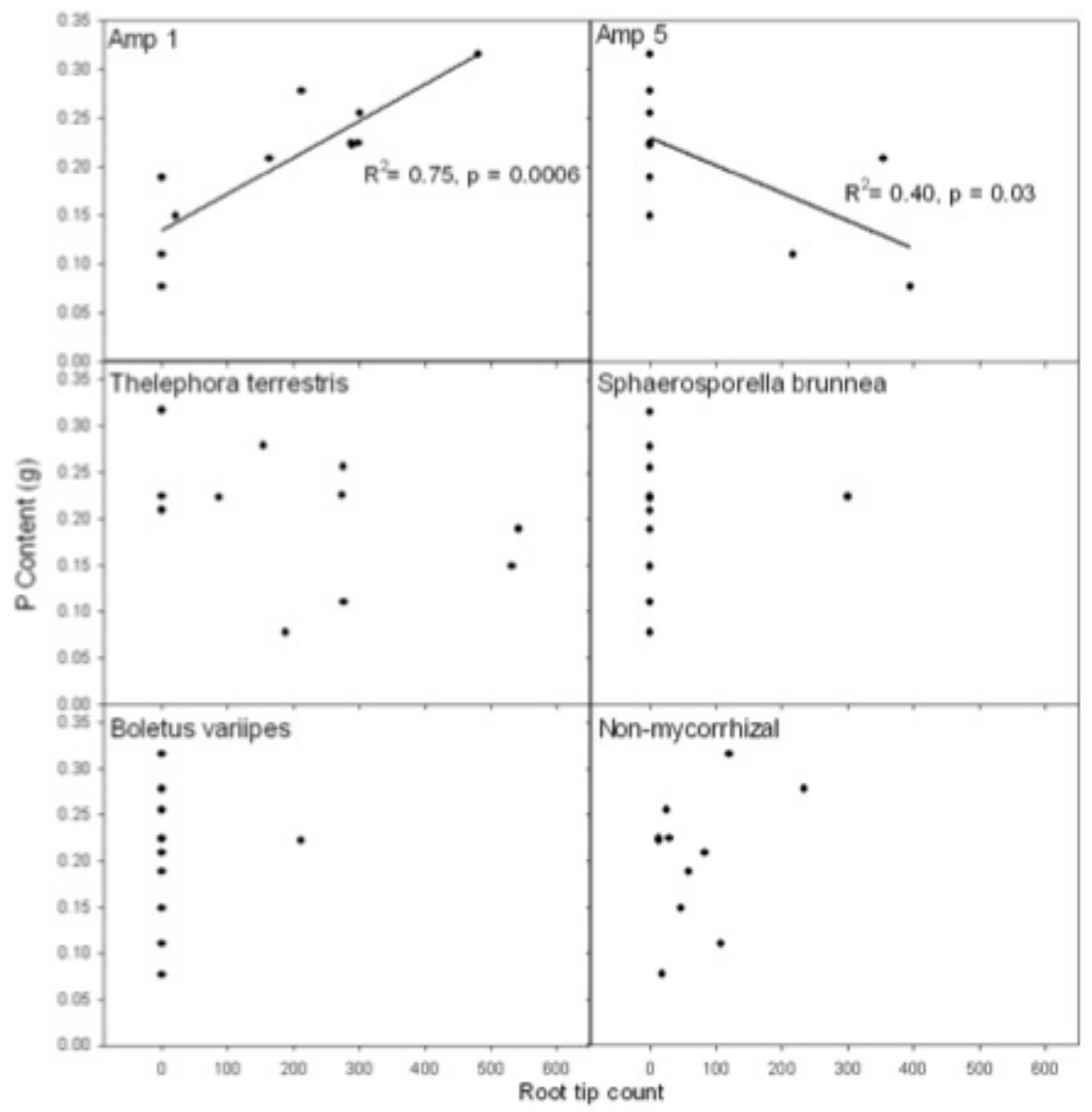

Fig 31.- Relationships between fungal species and foliar phosphorus content of unfertilized seedlings. A significant positive trend was observed in Amphinema sp. 1. A significant negative trend was observed in Amphinema sp. 5. 


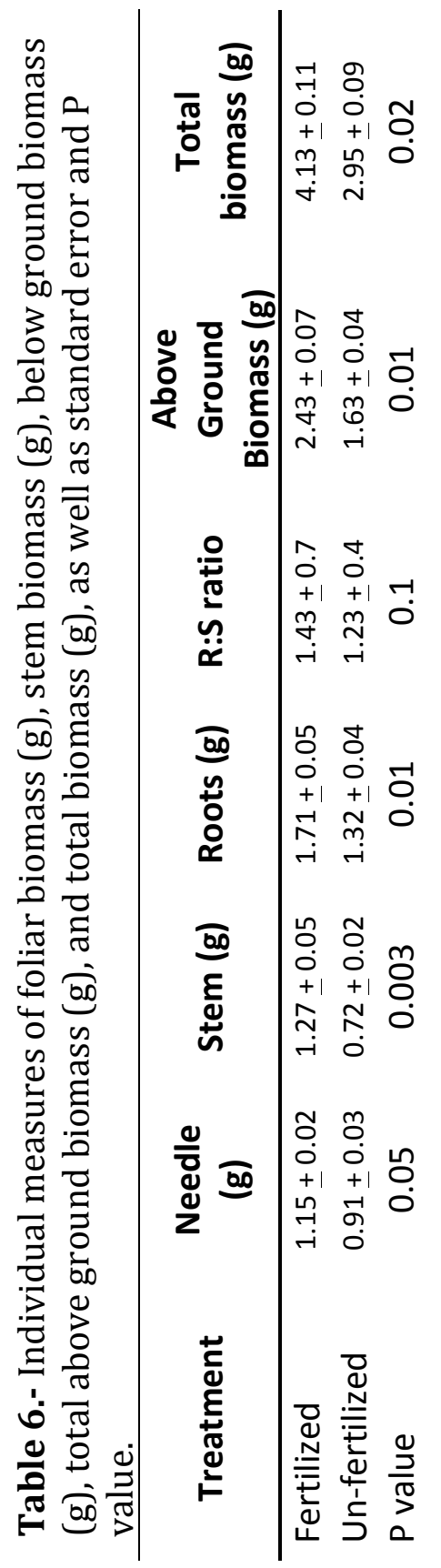




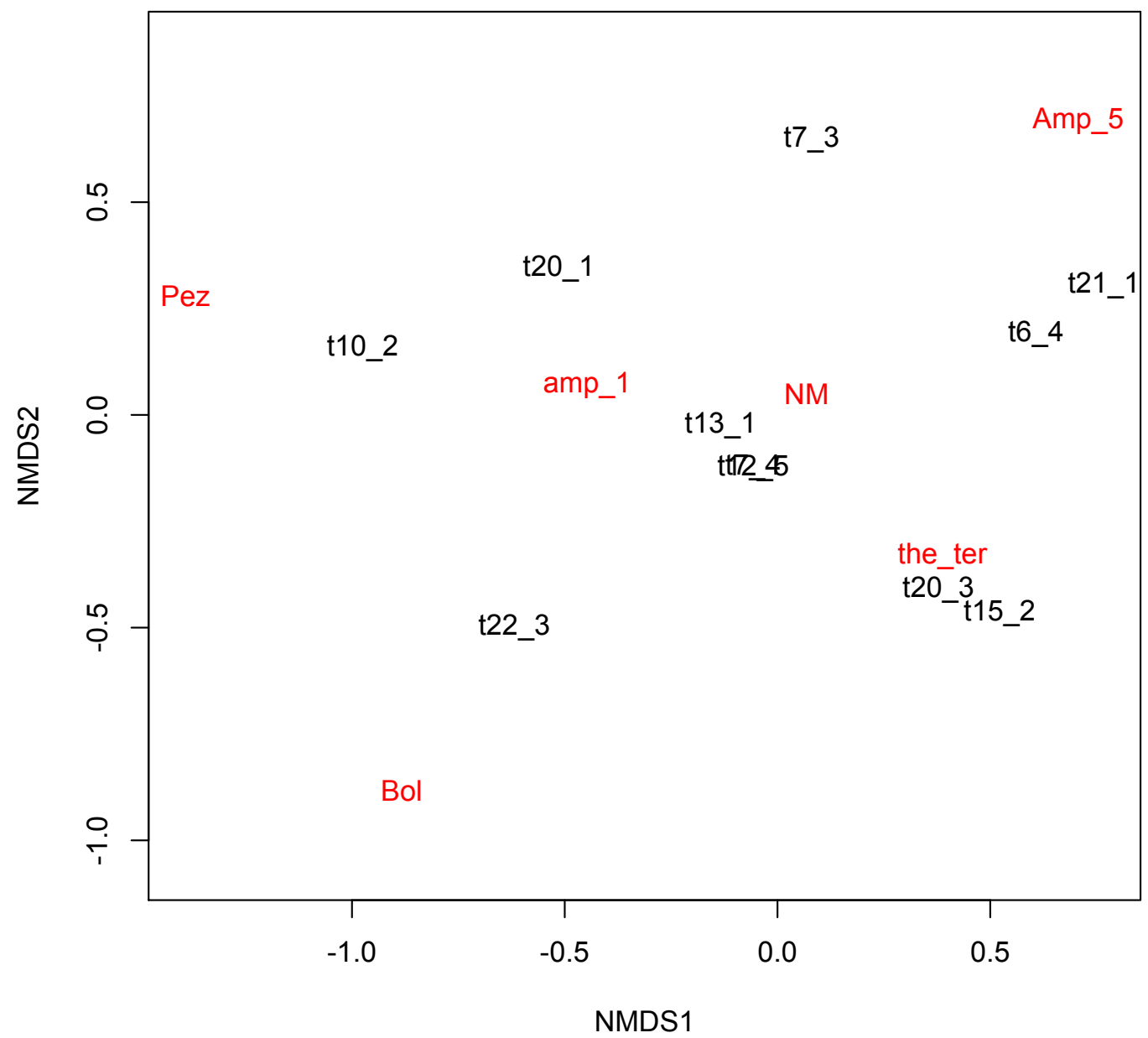

Fig 32.- Non-metric dimensional analysis using the R package VEGAN to determine significance of difference amongst total biomass, stem biomass, root biomass, needle biomass, and root to shoot ratio in unfertilized seedlings. Bol represents Boletus variipes, Pez represents Sphaerosporella brunnea, amp_1 represents Amphinema sp. 1, Amp_5 represents Amphinema sp. 5, the_ter represents Thelephora terrestris, and t\#_\# represent seedlings. There were no significant trends in the Envfit analysis. 


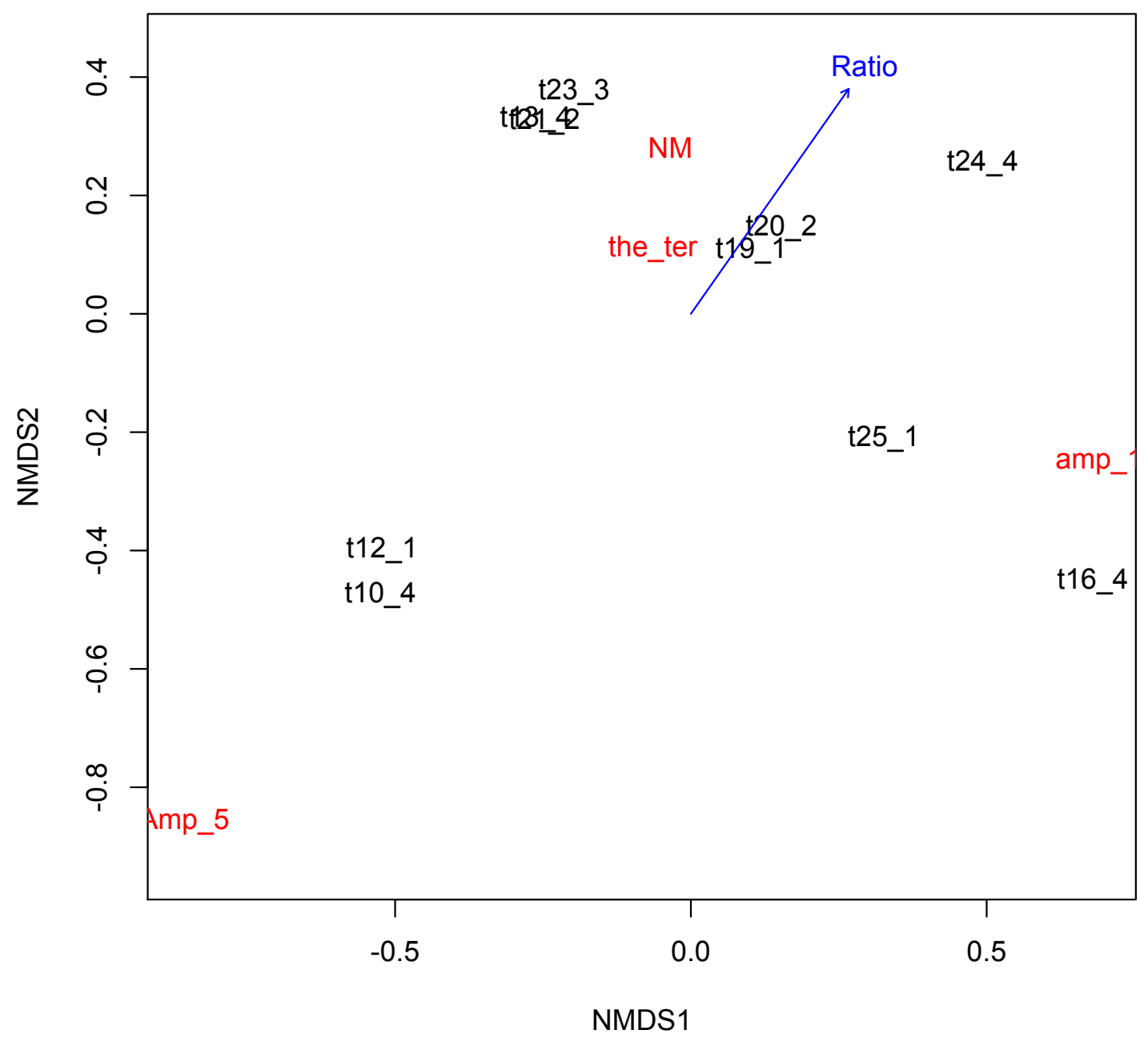

Fig 33.- Non-metric dimensional analysis using the R package VEGAN to determine significance of difference amongst total biomass, stem biomass, root biomass, needle biomass, and root to shoot ratio in fertilized seedlings. Bol represents Boletus variipes, Pez represents Sphaerosporella brunnea, amp_1 represents Amphinema sp. 1, Amp_5 represents Amphinema sp. 5, the_ter represents Thelephora terrestris, and $\mathrm{t \#} \#$ \# represent seedlings. For the Envfit analysis, red arrows indicate signicant trends $(\mathrm{p}<0.05)$, while blue arrows represent marginally significant trends $(\mathrm{p}<0.1)$. 


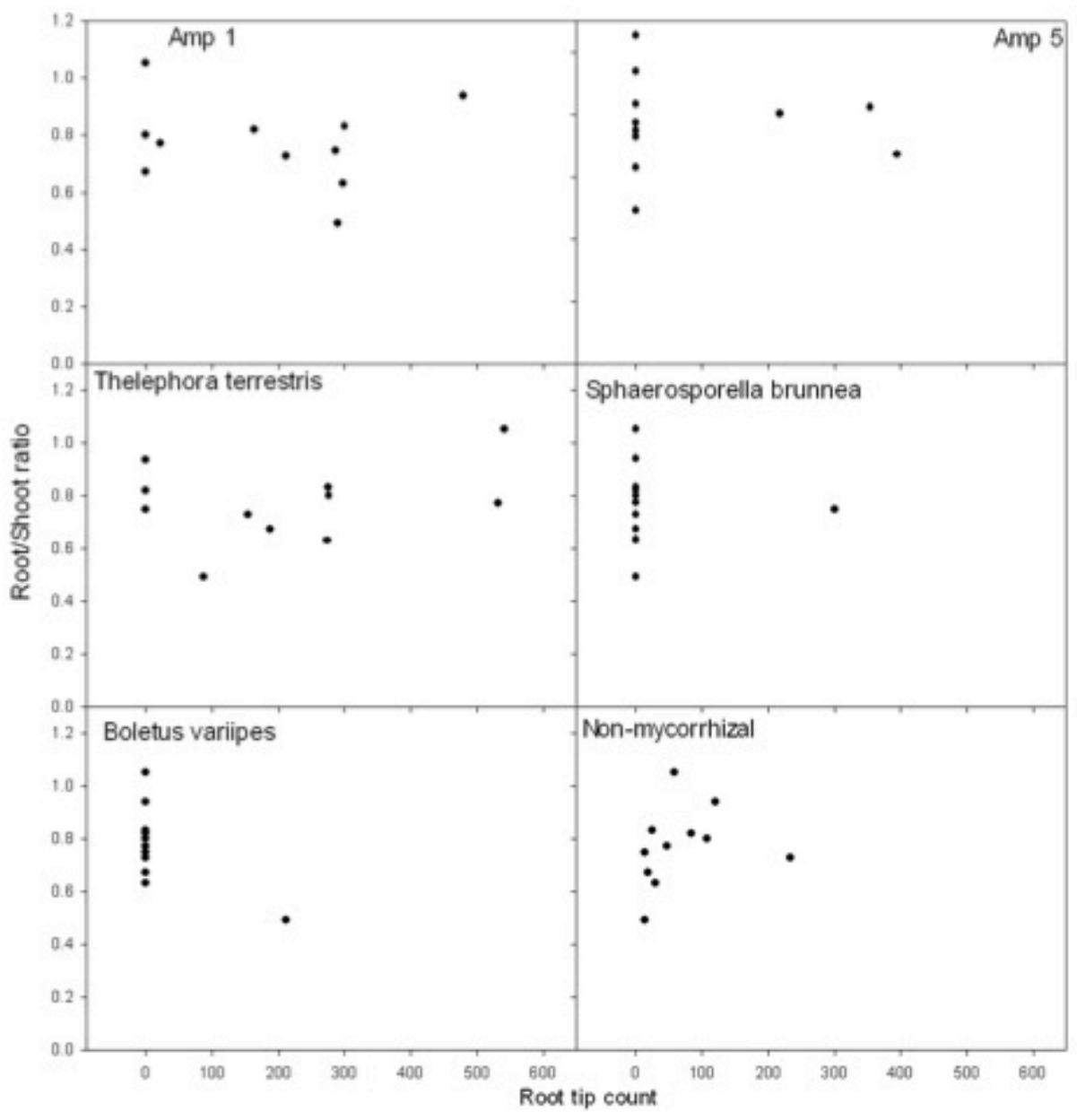

Fig 34.- Root to shoot ratios for unfertilized seedlings.. 


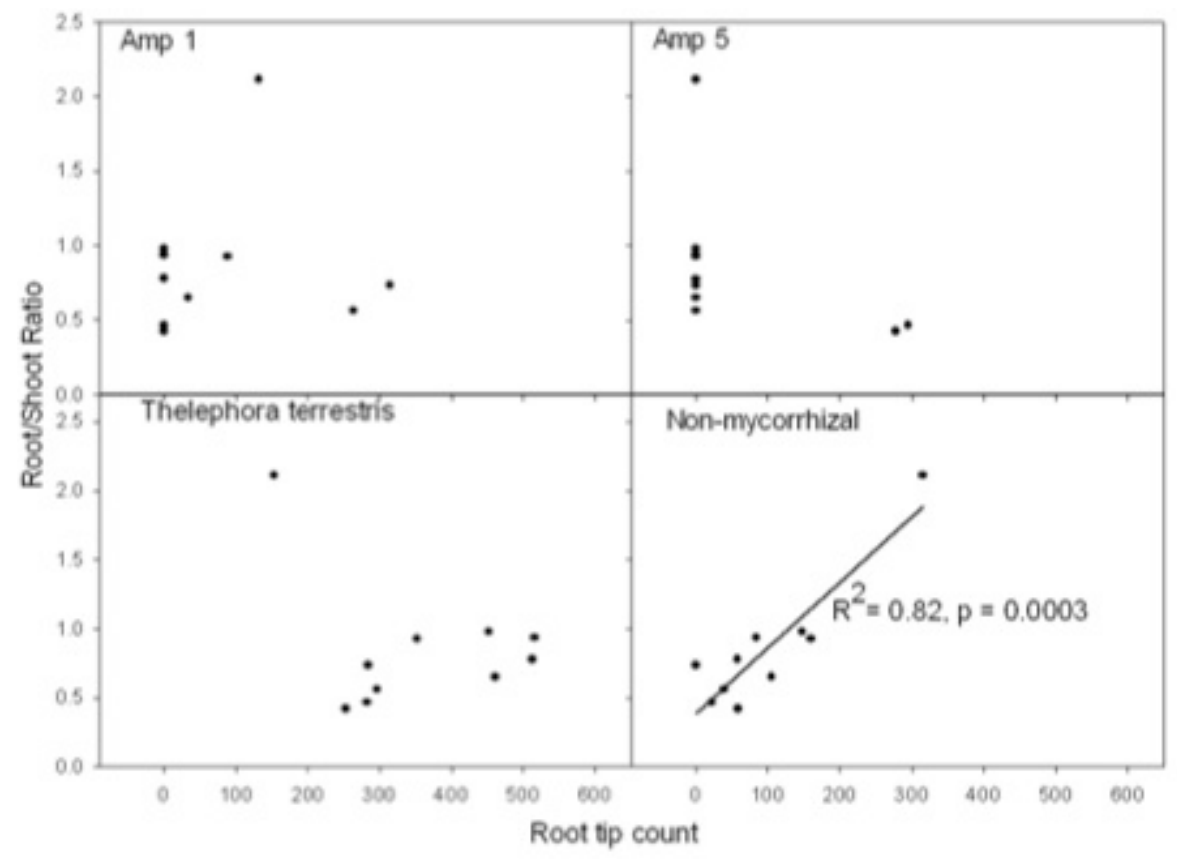

Fig 35.- Root to shoot ratios for fertilized seedlings. 
Table 7.- Limiting nutrients quantities

\begin{tabular}{lc}
\hline Nutrient & $\mathbf{m g} / \mathbf{k g}$ \\
\hline $\mathbf{N}$ & 10500 \\
$\mathbf{P}$ & 1000 \\
$\mathbf{K}$ & 2500 \\
$\mathbf{C a}$ & 1000 \\
$\mathbf{M g}$ & 500 \\
$\mathbf{B}$ & 2.5 \\
Mn & 10
\end{tabular}




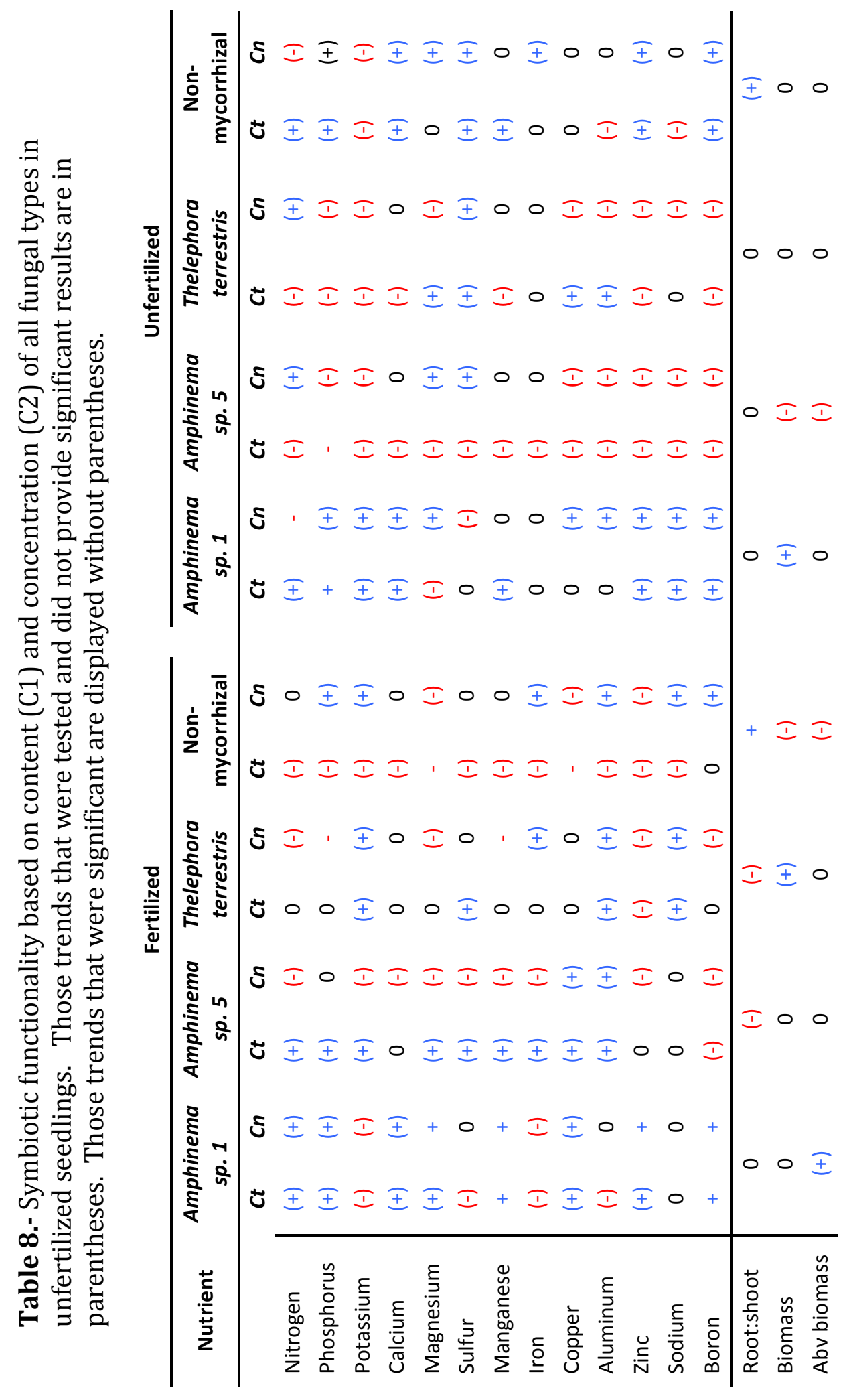

